\title{
El reto de la medición del antigitanismo: indicadores sobre discriminación y exclusión social hacia la población Romá en la Unión Europea
}

\author{
The Challenge of Anti-Gypsyism Measurement: Indicators on Roma's \\ Discrimination and Social Exclusion towards Roma in the European \\ Union
}

\author{
María Luisa Jiménez-Rodrigo \\ Universidad de Granada \\ Sonsoles Patricia Sánchez-Muros \\ Universidad de Granada
}

\section{RESUMEN}

En este artículo se presenta una revisión y evaluación de las fuentes secundarias de datos disponibles para la medición del antigitanismo a nivel europeo. A partir de estas fuentes, se propone un sistema de indicadores que aborda tres dimensiones fundamentales del antigitanismo: 1) actitudes de rechazo hacia la población Romá, 2) discriminación declarada por la población Romá en diferentes ámbitos sociales, y 3) exclusión social de la población Romá y materialización de esta en sus condiciones de vida. Los resultados revelan paradojas e inconsistencias entre las dimensiones del antigitanismo que permiten analizar distintas fuentes. Señalamos la necesidad de mejorar los instrumentos de medición del prejuicio, la discriminación y la exclusión social contra la población Romá, pero también de avanzar en el análisis de los mecanismos de dominación que fomentan la naturalización de las desigualdades sociales. 
PALABRAS CLAVE: Romá, antigitanismo, sistema de indicadores, medición, prejuicio, discriminación, exclusión social, Unión Europea

\section{ABSTRACT}

The present article shows a review and assessment of the secondary sources of data available to measure anti-Gypsyism at European level. Based on these sources, it proposed an anti-Gypsyism system of indicators organized into three key dimensions: $1^{\text {st }}$ ) rejection attitudes towards the Roma population, $2^{\text {nd }}$ ) discrimination reported by the Roma population in different social contexts, and $\left.3^{\text {rd }}\right)$ social exclusion of the Roma population in different aspects of their living standards. The results indicate the existence of paradoxes and inconsistencies between the three dimensions. We point out the need for significant improvement in the tools for measuring prejudice, discrimination and social exclusion towards the Roma population, but also to advance in the analysis of current mechanisms of domination that foster the naturalization of social inequality.

KEY WORDS: Roma, antigypsyism, discrimination, system of indicators, measurement, prejudice, discrimination, social exclusion, European Union

\section{INTRODUCCIÓN}

Históricamente, la población Romá, desde su llegada al continente europeo en el siglo XV, ha sido objeto de actitudes y comportamientos excluyentes por parte de la población mayoritaria. La discriminación institucionalizada, reflejada en acciones antigitanistas extremas (ejemplos notorios son La Gran Redada de 1749 en España o La Noche de los Gitanos -Zigeunernacht- en 1944 en Oświęcim, Polonia) ha intentado reiteradamente y a través de los siglos subsumir la minoría a la mayoría. Otra referencia histórica necesaria se sitúa en la última década del siglo XX, cuando la caída del bloque comunista y la transición política de Europa del Este hacia el capitalismo y la integración progresiva de nuevos miembros en la UE, provoca importantes migraciones Romá, especialmente en los años 1991 y 1992 desde Croacia y Bulgaria, y en 1995 desde la República Checa, Polonia y Eslovaquia (donde se producían importantes en conflictos étnicos) hacia economías más desarrolladas como Gran Bretaña, Francia, Alemania e Italia (Urh 2014). Estos movimientos despertarán de nuevo en las sociedades de acogida un 
sentimiento de amenaza y de miedo hacia la población Romá que se manifestará en nuevas formas de racismo moderno. Este nuevo racismo combina aspectos del racismo tradicional -directo, explícito, violento y basado en argumentos biológicos en muchos casos- con un rechazo menos evidente y ligado a la reproducción de imágenes negativas y criminalizadoras de la población Romá como grupo que se comporta de forma indeseable y que causa problemas de seguridad y de orden público.

Desde múltiples instancias políticas y sociales se viene señalando la necesidad de visibilizar la discriminación y la exclusión que enfrentan los grupos de origen Romá y de que sus problemáticas, necesidades e intereses sean incorporados en las políticas públicas (Cortés Gómez y End 2019). A partir del 2000, la Unión Europea adopta medidas legislativas para establecer un marco general para la igualdad de trato hacia minorías raciales y étnicas y para combatir ciertas formas y expresiones de racismo y xenofobia. La principal preocupación en la agenda política europea gira en torno a la integración (que no inclusión) de la población Romá (Carrera, Rostas y Vsyliüte 2017), en un marco de políticas centrado principalmente en el ámbito educativo y en la vivienda (Ciaian y Kancs 2016). Pese a ello, se mantiene y agrava el rechazo contra los grupos romaníes en la mayoría de las esferas sociales y económicas (FRA 2017a) bajo la ola de populismo xenófobo que actualmente se extiende por Europa. Respecto a otros grupos racializados, la población Romá un mayor rechazo por parte de la población mayoritaria (Valentine y McDonald 2004). Además, la normalización del antigitanismo afecta no sólo a las percepciones y opiniones de la población general sino también a las instituciones políticas y medios de comunicación (Hadziavdic 2012; Cortés Gómez y End 2019).

Una cuestión fundamental en la lucha contra el antigitanismo concierne a su medición, lo que genera discusiones metodológicas, políticas y éticas sobre la producción y uso de datos de carácter étnico. Por una parte, se ha planteado la necesidad de contar con instrumentos de medición y evaluación que permitan conocer las situaciones de exclusión y de desigualdad que afectan a la población Romá para poder desarrollar mejores y más eficaces políticas de inclusión y de lucha contra la discriminación (Makkonen 2016; Open Society European Policy Institute 2017; Comisión Europea 2018). Pero también se ha advertido sobre los usos abusivos y estigmatizadores que pueden producirse al recoger, interpretar y difundir datos sobre minorías étnicas (Reuss y Mack 2019). Por otro lado, la medición del antigitanismo implica dificultades y retos metodológicos que evidencian la necesidad de contar con marcos conceptuales sólidos y con fuentes 
válidas y fiables que permitan la comparación entre diferentes países (Ivanov, Keller y Till-Tentschert 2015).

En este trabajo se realiza una revisión de las principales fuentes de datos cuantitativos sobre discriminación y exclusión hacia la población Romá disponibles en el marco de la Unión Europea con objeto de establecer un sistema de indicadores sobre diferentes manifestaciones del antigitanismo. Para ello, se examinarán las posibilidades y las limitaciones de las fuentes existentes así como los posibles sesgos que pueden afectar a los datos producidos. Finalmente, se describirá la estructura del sistema de indicadores propuesto, ofreciendo datos actualizados y comparables entre distintos países de la UE sobre tres dimensiones centrales del antigitanismo: 1) el grado de rechazo social hacia la población Romá; 2) las experiencias de discriminación; y 3) las situaciones de exclusión social experimentadas por mujeres y hombres Romá en diferentes ámbitos sociales. Examinaremos, en la medida que así lo permitan los datos, las diferencias de género dentro de la población Romá.

\section{CONCEPTUALIZACIÓN DEL ANTIGITANISMO}

El concepto antigitanismo, después de décadas de desatención académica e institucional, ha ido ganando importancia dentro de los discursos políticos, académicos y sociales para enfatizar el carácter específico del racismo hacia la población Romá (Cortes Goméz y End 2019). El antigitanismo -cuyo origen histórico se sitúa en Rusia con la utilización en 1920 del término antiziganismo, paralelo al antisemitismo- fue incorporado tardíamente en el léxico institucional en las resoluciones del Parlamento Europeo en 2005, que adoptó por primera vez legislación específica contra la discriminación de base étnica para más tarde incluirla explícitamente en su agenda política a través de la Recomendación no13 de la Comisión Europea contra el Racismo y la Intolerancia (ECRI 2011). Hoy en día, los principales actores institucionales de la UE han incorporado el término antigitanismo $^{1}$ en su agenda (Carrera, Rostas y Vosyliüte 2017), siendo definido como:

\footnotetext{
${ }^{1}$ El concepto de "antigitanismo" y su abordaje empírico ineludiblemente plantea los debates en torno a los procesos sociales de definición y caracterización del "otro", y particularmente sobre lo que es "ser Romá" o "ser gitano". A esta compleja cuestión, que escapa al objetivo del presente artículo, han tratado de dar respuesta multitud de estudios antropológicos y sociológicos, que sitúan su núcleo en muy diferentes niveles (Ardevol 1986; Cantón 2004; Laparra 2007; González Enríquez 2010). Aquí nos
} 
Una forma específica de racismo, una ideología basada en la superioridad racial, una forma de deshumanización y de racismo institucional alimentado por una discriminación histórica, que se manifiesta, entre otras cosas, por la violencia, el discurso del miedo, la explotación y la discriminación en su forma más flagrante. [...] Es una forma de racismo particularmente persistente, violento, recurrente y banalizada (ECRI 2011: 4).

La Alianza Europea contra el Antigitanismo propone una definición operativa al identificar los diferentes elementos que confirman el antigitanismo:

El antigitanismo es una compleja [forma de] racismo, persistente e históricamente construida, contra grupos sociales identificados bajo el estigma "gitano" u otros términos relacionados e incorpora: 1) una percepción y descripción homogénea y esencial de estos grupos; 2) la atribución de características específicas a ellos [desviadas, estigmatizadas]; 3) las estructuras sociales discriminatorias y las practicas violentas que emergen en ese contextos, que tienen un efecto degradante y de ostracismo, que producen desventajas estructurales” (Alliance Against Antigypsyism 2019: 5).

A partir de esta definición, pueden identificarse dos esferas principales de manifestación del antigitanismo que ayudarán a estructurar el sistema de indicadores. Primero, la esfera ideológica de prejuicios, actitudes y creencias que sustentan un rechazo generalizado contra la población Romá. Esta dimensión se basa en la diferenciación entre ellos y nosotros, es decir, en identificar a la población Romá con el proceso de otredad (Kapralski 2016). El prejuicio es un elemento central del rechazo, que comprende las actitudes hostiles hacia una persona a la que se le presumen ciertos rasgos que se consideran propios de una categoría social, simplemente por el hecho de pertenecer a esa categoría social (Allport [1954] 1991). Toda vez que dichas creencias desencadenen reacciones emocionales y tendencias conductuales, esta actitud puede transformarse en actos de discriminación, segregación y violencia, que son formas elementales del racismo (Wieviorka 1992). Este marcado alejamiento se produce por su oposición

centraremos en la definición establecida por la Unión Europea para delimitar a los grupos Romá como población objeto de investigación y de intervención y que abarca una variedad de grupos que se autoidentifican como Sint, Kale, Travellers y otros grupos Romá (FRA 2013), aunque en España el término que se impone es el de "población gitana" (Fundación Secretariado General Gitano, sitio web). 
a los valores hegemónicos y exclusión del concepto de "civilizados" (End 2014: 42). De hecho, el epicentro del antigitanismo consiste en asumir que la población Romá representa un grupo desviado de la mayoría no-Romá, que todavía no ha aceptado ni internalizado las normas y valores de la sociedad dominante (Hadziavdic 2012). Se trataría de lo que se ha denominado antigitanismo razonable, donde el problema no somos nosotros sino ellos que violan derechos e incumplen obligaciones ciudadanas (Van Baarm 2014). Este proceso de "otredad" jerarquiza la diferencia y la convierte en desviación de las normas y valores dominantes. Los principales estereotipos atribuidos a la minoría ("vagos" "atrasados" o "sucios", junto cierto tipismo "exóticos", "nómadas" de "tradiciones arraigadas"), justifican una posición estructural inferior (Carrera, Rostas y Vosyliute 2017). Otra de las manifestaciones de antigitanismo asimila el carácter nómada atribuido sin distingos a los grupos Romá con la categoría de "migrantes", cuya condición merma el estatus legal, y por tanto, los derechos y libertades correspondientes a la ciudadanía europea (Corsi et al., 2008; Carrera, Rostas y Vosyliüté 2017). El antigitanismo también comprende discursos benevolentes y paternalistas. Todo ello legitimaría que la diferencia se torne en deficiencia, y consecuentemente, en desigualdad (Alliance Against Antigypsyism 2017).

La segunda esfera fundamental del antigitanismo concierne a la discriminación y exclusión social que enfrenta la población Romá en cuanto al acceso a los derechos de ciudadanía y a los recursos básicos para unas condiciones dignas de vida. La última encuesta de la Agencia Europea para los Derechos Fundamentales (FRA) sobre discriminación y minorías étnicas (FRA 2017a) advierte que el 41\% de la población Romá se ha sentido discriminada por su origen étnico y que un $80 \%$ vive por debajo del umbral de pobreza. Las manifestaciones del antigitanismo reflejadas en el plano de la exclusión social abarcan un amplio espectro de situaciones sistematizadas, según Carrera y colaboradores (2017), en el ámbito de la vivienda, la educación, los medios de comunicación, el empleo, el sistema judicial, el discurso político, y los servicios sanitarios (Cemlyn et al., 2009).

La exclusión sistemática que enfrenta la población Romá solo puede entenderse atendiendo a sus raíces estructurales. De hecho, las manifestaciones sistémicas e institucionales pueden ser detectadas en las políticas públicas, como se observa en los casos de segregación residencial, realojos y desalojos forzosos, expulsiones o las restricciones de libertad de movimiento dentro de la UE, que a día de hoy continúan produciéndose (ECRI 2011; FSGG 2016, 2018; Comisión Europea 2017). Al mismo tiempo, se constata la persistencia de prácticas segregacionistas 
escolares en centros públicos (Río Ruiz 2018), así como desigualdades en el acceso a prestaciones sanitarias, como reiteran los últimos estudios (UrbanosGarrido 2016; La Parra, Gil y Jiménez 2013), pese a la mayor frecuentación médica de la población gitana en comparación a la población general (MSSSI 2018).

Las situaciones de discriminación y de exclusión social se ven intensificadas por las desigualdades de género que enfrentan las mujeres Romá, tanto dentro como fuera de sus comunidades (Surdu y Mihais 2006; Fredman 2016), constituyendo el grupo más vulnerable a la múltiple discriminación y con mayor probabilidad de exclusión social y de pobreza respecto a toda la población de mujeres en general y también en comparación con los hombres Romá (Kócksé y Popa 2009). La estricta separación tradicional de roles de género junto con las estructuras de poder patriarcal dentro de sus comunidades (Gay Blasco 2011) impiden el desarrollo personal de niñas y mujeres, especialmente en el acceso a la educación y el empleo (Corsi et al., 2008; Lauritzen y Nodeland 2018). No obstante, algunos colectivos de mujeres gitanas están desafiando el enfoque tradicional y están conformando destacados movimientos feministas romaníes donde pueden encontrarse voces muy críticas (véase Caro Maya y Werner Boada 2018; Mesa de Mujeres Gitanas por la Igualdad, 2018). Otro ámbito donde las mujeres experimentan situaciones de desigualdad es el de la salud, especialmente en cuanto a las vulneraciones de sus derechos sexuales reproductivos (Watson y Downe 2017; Escobar-Ballesta, García-Ramírez, Albar-Marín et al., 2019), y en relación a la salud mental, como consecuencia de sostener, junto a unas condiciones de vida paupérrimas, sobrecargas emocionales como cuidadoras de familias en un contextos de racismo, discriminación y aislamiento social (Power 2004; Richardson 2006).

\section{EL ABORDAJE EMPÍRICO DEL ANTIGITANISMO}

\section{LOS DEBATES EN TORNO A LA PRODUCCIÓN DE DATOS DE CARÁCTER ÉTNICO}

La producción de datos de carácter étnico provoca un intenso debate sobre su pertinencia y necesidad ética y política en conexión con cuestiones más metodológicas acerca de la validez y la precisión en la medición de variables como como la "identidad" u "origen étnico" (Makkonen 2016). Por una parte, desde diversas instituciones internacionales se insta a producir y recoger datos que visibilicen las situaciones de discriminación y exclusión por motivos étnicos (Makkonen 2016; Comisión Europea 2018) para mejorar el alcance y efectividad de las políticas de atención e inclusión de los colectivos más vulnerables. Sin 
embargo, otras posturas -provenientes de contextos donde se han producido abusos y crímenes a raíz del recuento e identificación de minorías étnicas, como, por ejemplo, por el nazismo en Alemania- se muestran críticas con la producción de este tipo de datos por sus posibles efectos estigmatizadores y excluyentes $\mathrm{y}$, también, por el riesgo de manipulación desde planteamientos xenófobos y racistas ${ }^{2}$ (Reuss y Mack 2019). Por ello, algunos países de la UE como Francia, Alemania, Irlanda, Rumanía o Suecia- prohíben en sus legislaciones la recogida de datos sobre las características étnicas de su población (Open Society Foundation 2012).

Entre los países que sí recogen datos relacionados con la identidad u origen étnico de la población, existen enormes divergencias en las fórmulas empleadas para su producción. Por una parte, puede definirse la "afiliación étnica" mediante la auto-identificación, donde los individuos que participan en la encuesta son preguntados directamente por su afiliación étnica o grupo étnico de pertenencia, o a través de la hetero-identificación, en donde agentes externos fijan la identidad étnica de una persona o de una comunidad entera como Romá en base a determinados parámetros (Ivanov, Keller y Till-Tentschert 2015). Ambos métodos tienen sus limitaciones. La auto-identificación tiende a subestimar la población Romá por la influencia del estigma. Y la identificación externa, además de limitaciones técnicas ligadas a la naturaleza subjetiva de la etnicidad, presenta serias implicaciones éticas por el riesgo de vulneración de los derechos fundamentales de las personas que participan en las investigaciones. Frente a estos dilemas, se han propuesto diversas recomendaciones internacionales (CES 2015; Pavee Point Traveller and Roma Centre 2016; United Nations 2018) para ofrecer un marco consensuado de buenas prácticas. Estas guías apuntan la conveniencia de recoger la "afiliación étnica" en base a las declaraciones libres de los participantes en las investigaciones (lo que incluye también la posibilidad de responder varias filiaciones o de no responder ninguna), garantizándose en todo caso el anonimato y la protección de datos (Fay y Kavanagh 2019).

\footnotetext{
2 Ejemplos de ello se han observado recientemente con la propuesta del Exministro del Interior italiano Matteo Salvini de realizar un "censo de gitanos" con objeto de elaborar un plan de desalojos de campamentos Romá, y la reforma legal de Eslovaquia para producir estadísticas sobre "delitos de gitanos".
} 


\section{LAS ENCUESTAS EUROPEAS SOBRE ANTIGITANISMO}

Las encuestas europeas con información sobre antigitanismo pueden clasificarse en tres tipos ${ }^{3}$. En primer lugar, se encuentran las encuestas sociales que incluyen preguntas genéricas sobre actitudes y opiniones sobre el rechazo y prejuicio étnico y que incorporan algunos ítems sobre el rechazo hacia la población Romá. Es el caso de los Eurobarómetros sobre Discriminación, la Encuesta Social Europea, la Encuesta sobre Calidad de Vida (Eurofound) y la Encuesta Europea de Valores. Si bien estas encuestas producen información sobre actitudes, opiniones y prejuicios sobre minorías étnicas y poblaciones migrantes extrajeras, la inclusión de ítems específicos sobre prejuicios hacia la población Romá es bastante limitada. Lo habitual es que se utilice la etiqueta sobregeneralizadora "origen étnico" para dar cuenta de la diferencia étnica.

En segundo lugar, se encuentran las encuestas focalizadas en la población gitana (Roma targeted surveys) que también algunos países han realizado a nivel nacional ${ }^{4}$. A nivel europeo, destacan las elaboradas por el Programa de Naciones Unidas para el Desarrollo (PNUD), junto a otras instituciones internacionales, en 2004 y 2011, para conocer las condiciones de vida de la población Romá en distintos países del Centro y Sudeste de Europa (no participa España). Por otro lado, la Agencia Europea de Derechos Fundamentales (FRA) ha desarrollado distintas encuestas dirigidas a conocer las condiciones de vida y situaciones de discriminación y exclusión de la población gitana y de otras minorías étnicas. En 2008, se aplica la Roma and Travellers Survey en seis países miembros de la UE (Francia, Bélgica, Irlanda, Países Bajos, Suecia, y Reino Unido) y en 2011 la Survey on Discrimination and Social Exclusion of Roma in EU (en adelante, Roma Survey) y la Survey on Minorities and Discrimination in EU en 2011 y 2016 (en adelante, MIDIS-I y MIDIS-II, respectivamente). Estas dos encuestas constituyen dos fuentes de datos fundamentales para este trabajo, incluyendo entre los países participantes a España.

\footnotetext{
${ }^{3}$ Otros procedimientos de producción de datos cuantitativos sobre diferentes aspectos y manifestaciones del antigitanismo son los mapas territoriales, como los Atlas de las Comunidades Romá elaborados en Eslovaquia (en 2004 y 2013) y en Rumanía (en 2014), y los censos, como los producidos por Bulgaria, República Checa, Hungría, Rumanía y Eslovaquia (Ivanov, Keller y Till-Tentschert 2015).

${ }^{4}$ En el ámbito español, han sido desarrolladas por el Centro de Investigaciones Sociológicas, la Encuesta Sociológica a Hogares de la Población Gitana, 2006; y por el Ministerio de Sanidad, Consumo y Bienestar Social, la Encuesta Nacional de Salud a Población Gitana, 2006 y 2014.
} 
La Roma Survey se realizó como estudio piloto en $2011^{5}$ con el objetivo de proporcionar un diagnóstico de la situación de exclusión y discriminación de la población Romá en 11 países miembros de la UE (Bulgaria, Hungría, Polonia, Portugal, Rumanía, Eslovaquia, República Checa, Francia, Grecia, Italia y España). En esta encuesta se incluyen datos sobre las características sociodemográficas de todas las personas que componen los hogares seleccionados, así como su situación en relación al empleo, educación, vivienda, salud, discriminación y participación social. Además, recoge información sobre población no Romá del entorno cercano. Esta encuesta proporciona información sobre 61.271 personas (FRA 2013), por lo que se convierte en una de las fuentes más valiosas para conocer las condiciones de vida de la población Romá.

Por su parte, la MIDIS entrevista a distintos grupos étnicos y nacionales minoritarios en los 28 países de la Unión Europea, aunque la inclusión de la población Romá en la muestra solo afecta a un número muy reducido de países: Portugal, Hungría, República Checa, Croacia, España, Grecia, Eslovaquia, Rumanía y Bulgaria. La muestra total en este conjunto de países es de 7.750 personas de 16 o más años y recoge información diversa sobre discriminación y condiciones de vida de la población Romá en diferentes ámbitos sociales (pobreza y privación material, educación, empleo, vivienda, salud, confianza y participación, y conciencia de derechos) (FRA 2017b).

Una tercera estrategia para recabar información sobre las condiciones de vida de la población Romá es la introducción de la variable "identidad étnica" en los cuestionarios e instrumentos estadísticos oficiales para construir una submuestra de individuos auto-identificados como Romá (por ejemplo, en la Encuesta Social Europea, o en el caso de Hungría y Bulgaria en la Encuesta de Condiciones de Vida). Sin embargo, la muestra de población Romá suele ser muy pequeña dentro de estas encuestas generales, por lo que difícilmente pueden extrapolarse sus resultados. Además, la ausencia de indicadores relevantes para la inclusión de la población Romá hacen que estas herramientas no permitan conocer datos relativos a la discriminación o el prejuicio (Ivanov, Keller y Till-Tentschert 2015).

Una vez consideradas las diferentes fuentes de información, se seleccionarán para este trabajo, y por razones de comparabilidad y disponibilidad de

\footnotetext{
${ }^{5}$ Aunque se ha realizado el trabajo de campo de la segunda edición de la Roma Survey en 2018 y 2019, los datos de la primera edición de 2011 son los únicos disponibles hasta el momento.
} 
información, los Eurobarómetros sobre Discriminación, la Encuesta Social Europea y las encuestas producidas por la Agencia de Derechos Fundamentales: Romá Survey y MIDIS-II.

\section{REVISIÓN CRÍTICA DE LAS HERRAMIENTAS DE PRODUCCIÓN DE DATOS SOBRE ANTIGITANISMO}

Junto a los problemas de disponibilidad y comparabilidad que reúnen las fuentes de datos sobre antigitanismo, es preciso considerar otro tipo de limitaciones respecto a la capacidad de las variables y preguntas introducidas en los cuestionarios para aprehender las diferentes manifestaciones del rechazo contra la población Romá.

En primer lugar, en las principales encuestas europeas puede observarse un sesgo de sobregeneralización (Eichler y Burke 2006) al ignorar la diferencias entre grupos diversos que son aglutinados bajo la variable "minoría étnica". En estas encuestas generales apenas se incluyen ítems centrados en la discriminación contra la población Romá, preguntándose en la mayoría de las ocasiones por el prejuicio étnico en general. Junto a ello, la asimilación de la categoría "origen étnico" con otras variables como el color de piel o el origen geográfico o nacional ${ }^{6}$, impide identificar el grado de prejuicio antigitanista. Así, se unifica bajo la etiqueta de diferencia étnica a una vasta diversidad de grupos o características (como la procedencia extranjera, las creencias religiosas o la apariencia física) que sólo tienen en común ser distintos a la mayoría de la población. Otro sesgo antigitanista identificado en las encuestas sobre discriminación y prejuicio se refiere a la vinculación de la condición étnica Romá al origen inmigrante extranjero (se une el origen inmigrante extranjero con la identificación de grupos de diferente etnia/raza o no se alude a la población gitana nacional) (Carrera, Rostas y Vosyliūtè 2017).

Las variables que pretenden medir prejuicios y situaciones de discriminación, además, pueden presentar sesgos androcéntricos al centrarse muchas de estas preguntas en contextos donde tradicionalmente hay mayor presencia masculina, como el laboral o el político, infraestimando otros ámbitos de la vida cotidiana donde las mujeres Romá pueden experimentar mayor discriminación. El uso de

${ }^{6}$ Ver pregunta QC3 del Eurobarómetro sobre discriminación en la UE: when a company wants to hire someone and has the choice between two [...] which of the following criteria may [...] put one [...] at a disadvantage? The candidate's skin colour or ethnic origin. 
expresiones genéricas ("persona Romá") tampoco ayuda a captar diferentes grados de incomodidad y rechazo étnico en función del género respecto a las situaciones recogidas en la Encuesta Europea sobre Discriminación (2016) como en el entorno laboral, el acceso a posiciones de liderazgo político o la elección de pareja de hijos/as. Este planteamiento androcéntrico de las preguntas invisibiliza situaciones donde las mujeres Romá pueden presentar situaciones específicas de estereotipia, rechazo y exclusión, como así se ha evidenciado en el campo de la educación, el empleo, y el acceso a la salud y a los servicios y prestaciones públicas (Sordo 2018). Así también, las preguntas sobre violencia y acoso incluidas en las encuestas analizadas muestran insuficiencias para captar elementos diferenciales de género tan sustanciales como obviar el tipo de relación que une a la mujer con el agente agresor?.

Pese a las limitaciones y sesgos identificados en las fuentes de datos sobre antigitanismo, éstas constituyen una herramienta imprescindible en estos momentos para avanzar en el conocimiento de la situación de discriminación y exclusión de la población Romá en el contexto europeo. No obstante, todas estas insuficiencias habrán de tenerse en cuenta en el análisis de los datos ofrecidos por estas fuentes.

\section{HACIA UN SISTEMA DE INDICADORES SOBRE ANTIGITANISMO: APUNTES METODOLÓGICOS}

Para la construcción del sistema de indicadores que aquí se propone se seguirá el planteamiento clásico de Paul Lazarsfeld (1979). Éste parte de la definición teórica del concepto que se pretende medir, para pasar a su desagregación en sus dimensiones fundamentales susceptibles de aprehensión empírica. A continuación, y evaluando la calidad de la información empírica disponible, se seleccionarán los indicadores más pertinentes para medir los diferentes aspectos incluidos en las dimensiones identificadas. Por último, se calcularán en cada

\footnotetext{
${ }^{7}$ En las preguntas de la MIDIS-II que tratan de las situaciones de acoso y ataques físicos a la población Romá no se identifica a la pareja como agente agresor, sino que se engloba dentro de la categoría más amplia de "familia/miembro del hogar". De tal forma, se invisibiliza la violencia contra las mujeres por parte de la pareja al diluirse dentro de la denominada "violencia intrafamiliar". Este sesgo impide, por tanto, obtener información comparable sobre la incidencia de la violencia de género contra las mujeres Romá.
} 
dimensión su correspondiente índice sintético para obtener una visión global de la situación del fenómeno a observar.

La técnica del análisis de indicadores sociales ha adquirido un renovado impulso no solo para medir el bienestar social y la calidad de vida de las sociedades en general, sino también para la monitorización de la situación de grupos sociales vulnerables, como, por ejemplo, la población migrante extranjera, las mujeres, la población infantil y joven, y la población mayor (para una revisión internacional, véase Bericat y Jiménez Rodrigo 2019). En el caso de la población Romá, no existen hasta el momento índices sintéticos o compuestos de carácter comparativo internacional. Aunque se ha elaborado el Roma Inclusion Index (Decade of Roma Inclusion Secretariat Foundation 2014) -destinado a medir, en una selección de países europeos, la brecha en las condiciones de vida entre la población Romá y la población general-, éste no se aplica de forma comparada entre los países seleccionados, sino que ofrece resultados particulares en función de las fuentes disponibles en cada país. El sistema de indicadores que aquí se presenta persigue rellenar esta laguna ofreciendo datos actualizados y comparables entre los países europeos.

\section{DIMENSIONES DEL ANTIGITANISMO Y SELECCIÓN DE INDICADORES}

Una vez delimitado el concepto del antigitanismo es preciso descomponerlo teóricamente en dimensiones que sean susceptibles de aprehensión empírica para realizar un encaje entre la estructura teórica y la estructura empírica de indicadores. Este encaje es complicado, pues es habitual que las fuentes empleadas, por su carácter secundario, no satisfagan las exigencias conceptuales planteadas a nivel teórico. En el caso del antigitanismo, éste es sin duda un concepto mucho más amplio y complejo en comparación con la limitada información empírica a la que podemos acceder a través de las encuestas utilizables hasta el momento. Por ello, en la estructuración de las dimensiones del antigitanismo ha prevalecido el criterio de la consistencia teórica para cuidar la credibilidad y la interpretabilidad de los resultados ${ }^{8}$. Las fuentes existentes, pese a sus restricciones, nos permiten acceder a tres tipos de datos fundamentales sobre el antigitanismo (ver cuadro 1 en anexo):

\footnotetext{
${ }^{8}$ Como así ocurre en la construcción de otros índices para la medición de las desigualdades sociales como el Social Justice Index o el Migrant Integration Policy Index (MIPEX).
} 
D.1) Actitudes antigitanistas, en relación a la extensión del rechazo y al grado de discriminación y tensiones interétnicas percibido por parte de la población general contra la población Romá.

D.2) Experiencias de discriminación declaradas por las mujeres y hombres Romá en diferentes ámbitos sociales.

D.3) Situaciones de exclusión social respecto a diferentes aspectos de la calidad vida expresadas por mujeres y hombres Romá.

La primera dimensión referente a las actitudes antigitanistas consta de dos subdimensiones que tratan de aprehender dos niveles de rechazo. Por una parte, el rechazo interpersonal hacia la población Romá, sustentado en la declaración de incomodidad frente a la presencia Romá en distintos espacios sociales (laborales, políticos y sociales). Se compone de tres indicadores extraídos del Eurobarómetro de 2016 sobre Discriminación en la UE en relación al grado de incomodidad experimentada frente a que una persona de origen Romá o de otro grupo étnico ocupe un alto cargo político, sea compañero o compañera de trabajo, o pareja sentimental de un hijo o hija. Por otra parte, la percepción del grado de discriminación societal hacia la población Romá y de la existencia de antagonismo interétnico. Está integrada por tres indicadores tomados de la MIDIS II y de la Encuesta de Calidad de Vida de Eurofound y aborda la percepción de la extensión de la discriminación en función del origen étnico en general en el país, la opinión sobre el origen étnico como desventaja para acceder a un empleo, y la percepción de tensiones entre grupos étnicos y raciales. Los tres indicadores se refieren a origen étnico en general, pero han sido incluidos al no producirse indicadores más concretos sobre población Romá. Aun así, entendemos que son útiles para aproximarnos al clima de discriminación y conflicto en torno a las relaciones interétnicas.

La segunda dimensión recoge datos sobre las experiencias de discriminación, acoso y violencia declaradas por la población Romá. Esta dimensión contiene seis subdimensiones correspondientes a distintos ámbitos de la vida durante los últimos 12 meses: acoso y violencia (tanto personal como a personas del círculo familiar y social cercano), uso de servicios sanitarios y de la administración, empleo, educación, acceso a la vivienda e interacción en la vida cotidiana.

La tercera dimensión pretende medir las condiciones objetivas de exclusión social en las que puede encontrarse la población Romá. La exclusión social es entendida como un proceso multidimensional, que incluye no solo "la falta de 
ingresos y el alejamiento del mercado de trabajo, sino también un descenso de la participación social y una pérdida de derechos sociales" (Laparra et al., 2007). Por ello, esta dimensión incorpora varias subdimensiones donde se manifiestan los efectos de este proceso de pérdida de integración social: educación, empleo, ingresos, salud y acceso al sistema sanitario, vivienda y segregación residencial, acceso a la protección social, y participación social. Los indicadores utilizados provienen fundamentalmente de la MIDIS-II (2016), aunque se han completado para algunas subdimensiones y países con los datos de la Roma Survey de 2011.

\section{CÁLCULO DE LOS ÍNDICES SINTÉTICOS}

Para las distintas dimensiones y subdimensiones se han calculado, respectivamente, índices sintéticos que permitirán resumir en un solo valor la situación de los países europeos respecto a los distintos componentes del antigitanismo. Teniendo en cuenta las distintas realidades abordadas por las tres dimensiones (y que, como veremos en el análisis de los resultados, entran en contracción), no se ha estimado conveniente calcular un índice global, en línea con lo argumentado por Van de Kerk y Manuel (2008). Estas medidas parciales nos servirán para establecer un marco de referencia comparativo que permita marcar la intensidad de las diferentes manifestaciones del antigitanismo y establecer relaciones entre sus dimensiones.

Aunque hay diferentes procedimientos para el cálculo de índices (Nardo et al., 2008), aquí empleamos la media geométrica (utilizada, por ejemplo, para el cálculo del Índice de Desarrollo Humano) para evitar la influencia de resultados extremos -positivos o negativos- que compensen la puntuación final de los países, de forma que la obtención de malos resultados en una dimensión no se contrarreste con la obtención de buenos resultados en otra (UNDP 2018). Para solventar el problema de los valores perdidos que se da en algunos indicadores para determinados países (principalmente, debido a la falta de representatividad de las muestras focalizadas en la población Romá cuando se desagregan por sexo), se ha optado por no incluir este dato en el cálculo de la media geométrica. $\mathrm{Al}$ encontrarse todos los indicadores en una misma escala de medida (porcentajes de población) no es necesario aplicar procedimientos de estandarización. Con objeto de simplificar la construcción y facilitar la interpretación de los índices no se emplea ninguna ponderación en el cálculo de los índices parciales. No obstante, se ha cuidado que el número de indicadores de cada subdimensión se encuentre equilibrado para evitar una descompensación en la importancia concedida a los diferentes indicadores (Greco et al., 2018). Finalmente, los 
valores de los índices se interpretan en una escala de 0 a 100, indicando 0 la mejor situación y 100 la peor situación posible.

Si bien las medidas sintéticas muestran limitaciones en cuando a la simplificación de la información sobre fenómenos y contextos complejos, constituyen una herramienta útil para realizar comparaciones entre diferentes países y monitorizar en el tiempo el grado de extensión del antigitanismo y evaluar el efecto de las políticas antidiscriminación 9 .

\section{RESULTADOS}

$\mathrm{El}$ análisis de los indicadores sobre antigitanismo ofrece sugerentes resultados, no tanto por su solidez sino por las paradojas e inconsistencias que revelan, lo que lleva al planteamiento de nuevos interrogantes e hipótesis sobre la medición de un fenómeno tan complejo y multifacético. En la tabla 1 (en anexo), se pueden observar los valores generales de los índices correspondientes a las tres dimensiones centrales.

La primera inconsistencia se produce al relacionar las tres dimensiones centrales del antigitanismo. La situación de exclusión social es la que presenta peores valores en el conjunto de los países europeos, muy por encima del contexto actitudinal antigitanista señalado por la población general y, sobre todo, de las declaraciones de discriminación expresadas por la propia población Romá. De hecho, se da un fuerte contraste entre las condiciones materiales de exclusión de la población Romá con la interiorización de esas condiciones como producto de la discriminación (gráfico 1).

\footnotetext{
${ }^{9}$ La importancia de las herramientas sintéticas para la evaluación de las políticas de inclusión social y no discriminación es reconocida por la Comisión Europea, que ha elaborado diversos índices compuestos para mejorar el conocimiento de distintas problemáticas como la exclusión social, la pobreza, la desigualdad de género o la justicia social (véase, por ejemplo, la página web del Competence Centre on Composite Indicators and Scoreboards, https://composite-
} indicators.jrc.ec.europa.eu/). 
Gráfico 1. Distribución de los índices de antigitanismo en la UE, según las diferentes dimensiones.

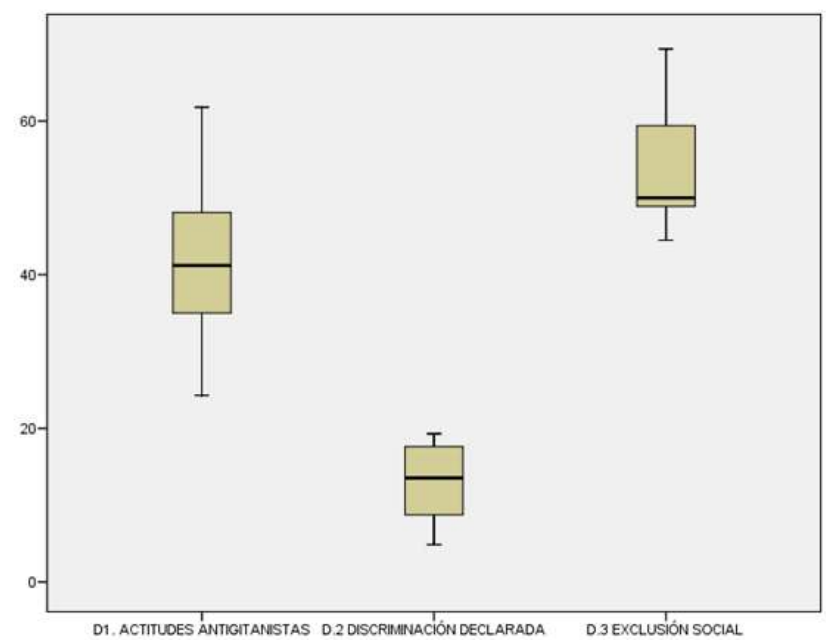

Fuente: Elaboración propia a partir de diversas fuentes secundarias (véase cuadro 1).

Estas discrepancias pueden explicarse en función de diferentes hipótesis (también aplicables a las inconsistencias y paradojas que se relatarán a lo largo de los siguientes epígrafes). La primera hipótesis es metodológica. Esto es: las herramientas de producción de datos pueden contener sesgos que afectan a su validez y fiabilidad para producir información sobre antigitanismo, y en particular, en relación a la producción de datos subjetivos sobre prejuicio, rechazo y discriminación percibida. Respecto a la medición del prejuicio y el rechazo contra la población Romá, los sesgos sobregeneralizadores ya apuntados impiden obtener información precisa sobre el rechazo específicamente antigitanista. Además, no puede obviarse la influencia del sesgo de la deseabilidad social, donde las actitudes socialmente reprobables quedan infraestimadas (Cea D’Ancona 2009).

Por otro lado, se ha advertido de las dificultades de la medición de la discriminación autodeclarada a partir de encuestas (Pager y Shepherd 2008). Pueden darse dos tipos fundamentales de errores. El primero: que las personas que han sufrido trato discriminatorio no lo identifiquen ni lo expresen como tal. $\mathrm{Y}$ el segundo: que las personas perciban trato discriminatorio donde no existe (o al menos no de la forma en que éste es definido por las personas investigadoras) (Russell et al., 2008). En este sentido, la forma de preguntar por las experiencias 
de discriminación ofrece diferentes resultados. Así se ha observado una subestimación de las situaciones de discriminación si se pregunta de modo general (" ¿ha experimentado discriminación en el trabajo en los últimos 12 meses?") que si se pregunta por situaciones específicas de discriminación (por ejemplo, en el ámbito laboral: no ser contratado/a, ser despedido/a, cobrar menos, no ser promocionado/a) (ALTER 2014).

En relación con lo anterior, la segunda hipótesis que podría explicar la baja percepción de discriminación por parte de grupos que presentan una alta tasa de exclusión social, se refiere a la normalización de los procesos de desigualdad y de discriminación como resultado de la interiorización de las relaciones de dominación (Bourdieu 2007). Como han mostrado otros estudios sobre discriminación, las experiencias percibidas por los grupos vulnerables suelen mantenerse en niveles muy bajos (Cea D’Ancona y Vallés 2018). Y aunque hay mayor conciencia de derechos de las víctimas, la discriminación apenas se denuncia, lo que puede indicar cierta naturalización o resignación frente a situaciones de trato discriminatorio que no logran captar las preguntas de los cuestionarios.

\section{ACTITUDES ANTIGITANISTAS}

El contexto actitudinal antigitanista es altamente variable entre los distintos países de la UE. En términos generales, los países que registran un mayor grado de rechazo contra la población Romá son República Checa y Grecia, seguidos de Bulgaria, Eslovaquia, Chipre e Italia, especialmente en lo que se refiere al rechazo interpersonal (tabla 2 en anexo). Estos son países en donde se ha producido una expansión de ideologías racistas y xenófobas -que incluso han llegado a obtener representación política en los gobiernos-, además de la persistencia de una significativa discriminación institucional (FSGG 2016, 2018), que ha llevado a algunos de estos países a ser objeto de infracción por parte de la Comisión Europea ${ }^{10}$.

Examinando las dos subdimensiones que componen esta dimensión, se observa una significativa paradoja respecto a la falta de correlación entre el rechazo interpersonal hacia personas Romá y la percepción de discriminación étnica societal. Esto puede deberse a que ambas dimensiones siguen dinámicas diferentes. Mientras que el rechazo interpersonal hacia personas Romá, o de

${ }^{10}$ Es el caso de Republica Checa, Eslovaquia y Hungría que han sido sancionados por sus políticas de segregación escolar (Comisión Europea, 2017). 
origen étnico distinto, obedece al efecto de prejuicios y estereotipos negativos hacia determinados grupos, la percepción de la discriminación societal -basada en las opiniones y creencias acerca de si la sociedad (no uno mismo) es discriminatoria respecto a determinadas minorías- puede estar motivada por una mayor concienciación o sensibilidad respecto a las desigualdades sociales. $\mathrm{O}$ también por la influencia del citado sesgo de deseabilidad social que, como ha indicado Johnson y Van de Vijver (2003), está mediado culturalmente, variando en función del sistema de valores imperante en diferentes contextos sociales.

Gráfico 2. Contextos antigitanistas en función del rechazo interpersonal hacia la población Romá y la discriminación étnica societal.

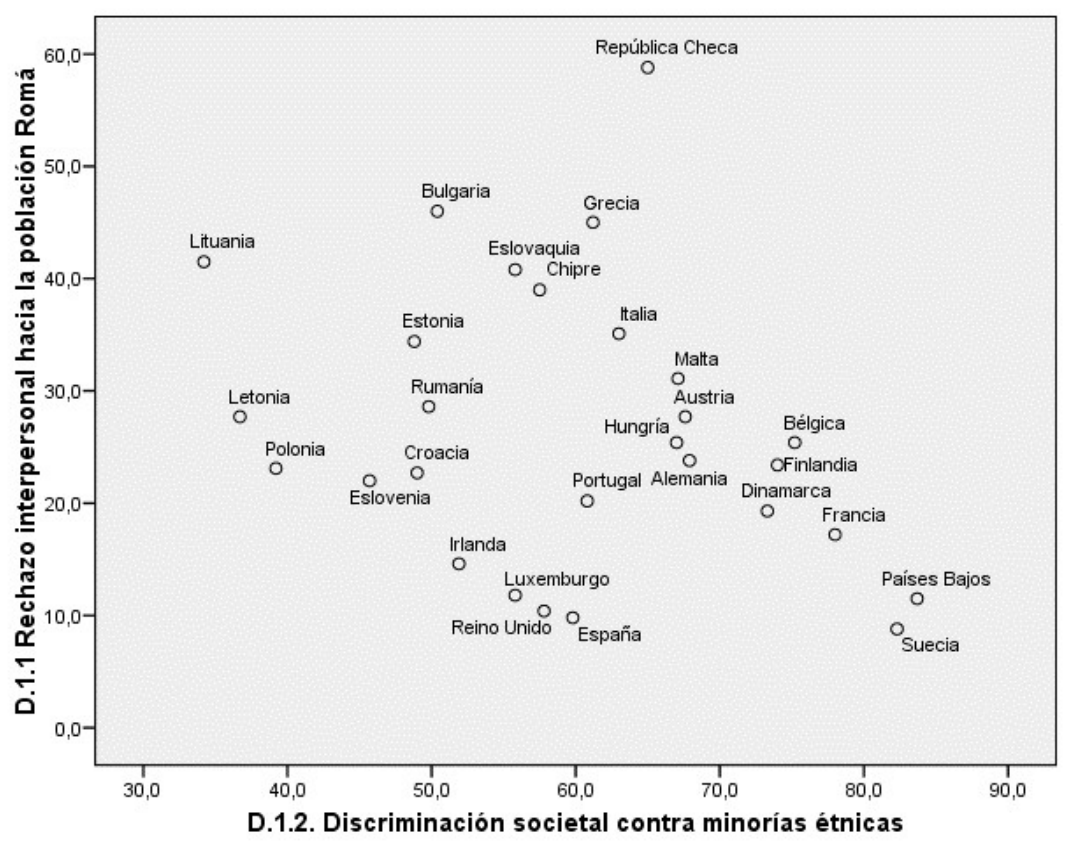

Fuente: Elaboración propia a partir de diversas fuentes secundarias (véase cuadro 1).

En este sentido, encontramos diferentes situaciones. El gráfico 2 muestra una clara polarización entre la nueva y la vieja UE (es decir, los países anexados con posterioridad o anterioridad al 2000). Así los países que se incorporaron a la UE en la ampliación de 2004 (República Checa, Estonia, Letonia, Lituania, Polonia, Eslovaquia y Eslovenia, y los dos microestados de Malta y Chipre) y 2007 
(Bulgaria y Rumanía), presentan mayor rechazo interpersonal y menor percepción de discriminación societal que los países nórdicos (Suecia, Finlandia, Dinamarca) y del centro de Europa (Holanda, Bélgica), junto con la fundacional Francia, que muestran menor rechazo interpersonal y mayor percepción de discriminación societal. Respecto a la destacada posición de Grecia (anexada a la UE en 1981), cabe destacar que ingresó como miembro de la zona euro en 2001.

\section{EXPERIENCIAS DE DISCRIMINACIÓN DECLARADAS POR LA POBLACIÓN ROMÁ}

La información sobre experiencias de discriminación declaradas por la población Romá es bastante más limitada al sustentarse en las encuestas específicas de FRA, aplicadas a un reducido número de países. Los ámbitos de mayor discriminación también varían en función de los países, aunque es en el ámbito de la violencia y el acoso donde más experiencias discriminatorias por origen étnico se expresan. A continuación, destaca la discriminación en la interacción social cotidiana, en el empleo y en el acceso al sistema sanitario y a los servicios públicos. Respecto al acceso a la vivienda, y aunque faltan datos por la reducida muestra, cabe destacar la alta incidencia de discriminación residencial en República Checa y España (tabla 3 en anexo).

Los países donde mujeres y hombres Romá señalan mayor grado de experiencias de discriminación son Croacia, República Checa, Eslovaquia y Grecia. Estas elevadas puntuaciones se explican en mayor parte por el elevado nivel de violencia y acoso que señala la población Romá en estos países (especialmente los hombres), junto a la marcada discriminación laboral que afecta especialmente a los hombres croatas y griegos. Estos países también registran, en general, índices muy altos de discriminación en salud (Grecia), educación (Croacia), vivienda (República Checa) e interacción social (Grecia). Eslovaquia, República Checa y Grecia también presentan un alto nivel de actitudes antigitanistas, lo que converge con el mayor malestar de la población Romá en cuanto a las experiencias declaradas de discriminación. Sin embargo, Croacia presenta un caso particular, ya que pese al alto porcentaje de población Romá que se siente discriminada, se observa una baja percepción de discriminación societal, aunque sí se corresponderá, como veremos, con las puntuaciones máximas de exclusión social. Esto puede explicarse por el ascenso de ideologías ultranacionalistas y xenófobas -que han calado también en los discursos políticos e institucionales- y la escalada de delitos de odio, denunciados por la Comisión Europea contra el Racismo y la Intolerancia (ECRI 2018). 
Hungría, Rumanía y Bulgaria, países con un alto porcentaje de población Romá, alcanzan menores puntuaciones en cuanto a las experiencias de discriminación declaradas, debido fundamentalmente a las menores situaciones de violencia y acoso declaradas, y a la reducida exclusión laboral. España y Portugal representan casos específicos, pues las fuentes de discriminación se concentran no tanto en la violencia y acoso, sino en el empleo (Portugal), vivienda (España), e interacción social (Portugal y España).

$\mathrm{Si}$ atendemos a las diferencias de género, en términos generales los hombres Romá expresan mayores situaciones de discriminación, particularmente referidas a situaciones de acoso y violencia, discriminaciones laborales, en el trato con el sistema sanitario y la administración, y en el contexto educativo. Cabe destacar la situación de República Checa que rompe con esta tendencia al ser las mujeres Romá las que manifiestan mayores situaciones de discriminación (particularmente, en cuanto a violencia y acoso, y empleo). El acceso a la vivienda es señalado en mayor medida por las mujeres residentes en República Checa y España. Pero, sobre todo, es en la interacción social cotidiana (acceso a tiendas, restaurantes y locales de ocio, y uso de transporte público) donde en mayor medida destaca la discriminación declarada por mujeres Romá. Este tipo de discriminación ha sido enfatizada por los estudios que han analizado la discriminación interseccional que enfrentan las mujeres gitanas (Sordo 2018).

Esta baja percepción de la discriminación por parte de las mujeres Romá contrasta con los estudios que evidencian las peores condiciones de vida que enfrentan las mujeres respecto a los hombres de sus comunidades (Surdu 2006; Corsi et al., 2008; Kócksé y Popa 2009; FRA 2014). De nuevo, podemos aplicar las dos hipótesis señaladas anteriormente. La hipótesis metodológica que apunta a la presencia de sesgos etnicistas y androcéntricos que dificultan la captación empírica de las experiencias de discriminación. Y, por otro lado, la hipótesis de la naturalización de las relaciones de dominación que impiden a los grupos más vulnerables identificar y señalar determinadas situaciones como discriminatorias.

\section{EXCLUSIÓN SOCIAL}

Las situaciones de exclusión social que experimenta la población Romá en su conjunto alcanzan diferentes niveles de gravedad en función de los ámbitos y los países considerados. En términos generales, es Croacia el país europeo que presenta peores resultados en cuanto a la exclusión social de la población Romá, seguido de Grecia y Bulgaria. El ámbito de exclusión social más grave es el que afecta a las condiciones económicas. Teniendo en cuenta que el valor 100 señala 
la peor situación posible, en la tabla 4 (en anexo) se observa como en Croacia, Grecia, Italia, España, Francia y Portugal prácticamente la totalidad de la población Romá está en situación de pobreza. La exclusión educativa es central y especialmente visible en las elevadas tasas de abandono escolar temprano de las mujeres en Grecia, Francia, Portugal e Italia.

En cuanto a la exclusión laboral, la información que compone esta subdimensión es muy limitada, puesto que las encuestas disponibles no proporcionan datos sobre las condiciones laborales, aspecto fundamental para abordar de forma más completa la exclusión del empleo. De tal forma, las puntuaciones de este índice resultan engañosas, pues en algunos países se registra una alta participación laboral (especialmente de los hombres), pero sin embargo ésta es muy precaria y carente de derechos, como indican los estudios disponibles en España (Laparra 2007; FSGG 2018). Croacia (seguida de España) vuelve a alcanzar los peores resultados respecto a la exclusión en el empleo, y son las mujeres Romá quienes enfrentan en mayor medida este apartamiento del mercado laboral, fundamentalmente por su adscripción a los trabajos de cuidado.

En relación a la exclusión sanitaria, las peores posiciones se registran en Croacia y las más favorables, en Francia, Portugal, España o Grecia. El acceso a la protección social en situaciones de vulnerabilidad (como el acceso a pensiones en la vejez o el apoyo en la búsqueda de empleo) apunta valores muy negativos, especialmente en Grecia, Hungría y Croacia. La exclusión respecto a la vivienda también alcanza puntuaciones alarmantes en Croacia, Italia y Rumanía, donde casi la totalidad de la población vive en zonas segregadas o/y en malas condiciones habitacionales. En cambio, Eslovaquia y Portugal, presentan mejores puntuaciones. Por último, la exclusión respecto a la participación social y política a través de la implicación en asociaciones y el ejercicio del derecho al voto presenta peores situaciones en Croacia y Grecia.

$\mathrm{Si}$ atendemos a las diferencias de género, las mujeres Romá presentan, en general y en todos los países, peores condiciones de vida, sufriendo mayor exclusión en los ámbitos educativo y laboral. También apuntan una mayor situación de exclusión en el uso de servicios de salud, participación social y acceso a la vivienda. En cuanto a la exclusión económica no se observan grandes diferencias entre mujeres y hombres, ya que el indicador empleado se refiere a las características del hogar y no a las situaciones individuales. Esta situación, como se apuntaba en el epígrafe anterior, resulta contradictoria con los menores índices de expresión de discriminación por parte de las mujeres Romá. 


\section{CONCLUSIONES}

En este trabajo se ha realizado una revisión de las principales fuentes cuantitativas disponibles a nivel europeo que proporcionan datos relevantes para el estudio de diferentes dimensiones del antigitanismo con el propósito de articular un sistema de indicadores que ayude a conocer, dentro del marco europeo, el grado de rechazo, discriminación y exclusión contra la población Romá. Este sistema de indicadores reúne la ventaja de reducir una amplia información dispersa en unas pocas medidas que faciliten la identificación por países de los ámbitos en que se producen manifestaciones antigitanistas. Esta reducción implica, no obstante, limitaciones al obviar la complejidad y la diversidad intrínseca de los grupos Romá, así como las variaciones de las problemáticas antigitanistas en diferentes contextos socioculturales. Pese a ello, y siempre salvaguardando el respeto de los derechos humanos, el desarrollo de procedimientos de medición de las condiciones de antigitanismo es fundamental para orientar las políticas públicas de inclusión y conocer el grado de avance hacia sociedades más igualitarias e inclusivas.

Podemos extraer dos conclusiones centrales a este trabajo. La primera conclusión se refiere a las limitaciones de las fuentes disponibles para la medición del antigitanismo. Existe una diversidad de fuentes para abordar diferentes aspectos del prejuicio, la discriminación y la exclusión contra las minorías étnicas, en general, y contra la población Romá, en particular. Sin embargo, éstas se muestran insuficientes por su dispersión y por su falta de homogeneidad y comparabilidad entre países. Las fuentes europeas focalizadas en la población Romá se refieren a un número muy reducido de países, y que además es variable en función de la encuesta de la que se trate. Todo ello, dificulta la elaboración de un sistema estructurado, comparable y periódico de indicadores sobre antigitanismo.

Otra dificultad metodológica se refiere a los sesgos observados en las preguntas destinadas a captar diferentes componentes del antigitanismo, como los sesgos etnicistas sobregeneralizadores y los sesgos androcéntricos que impiden obtener datos precisos sobre el rechazo antigitanista y, en concreto, sobre sus diferentes manifestaciones en función del género. La naturaleza sesgada de algunos de estos indicadores afecta a la validez del sistema de indicadores propuesto, por lo que desde una perspectiva autocrítica los resultados han de considerarse provisionales y objeto de revisión. En todo caso, la identificación de estos sesgos señala la necesidad de revisar las preguntas incluidas en los cuestionarios para la 
medición de la discriminación de forma que se incremente su precisión respecto a la diversidad interétnicas y su sensibilidad de género.

Las inconsistencias y paradojas encontradas en este trabajo también apuntan a los posibles problemas metodológicos en la medición de la discriminación percibida, al constatarse una muy baja tasa de identificación de situaciones de discriminación por parte de una población que sufre unas elevadas tasas de exclusión social, especialmente entre las mujeres. Las insuficiencias metodológicas de las fuentes disponibles indican la necesidad de avanzar en las estrategias cuantitativas de medición de un fenómeno complejo y que atañe a una población muy difícil de delimitar y acceder. Y por ello, precisamente, las técnicas cualitativas se convierten en una herramienta fundamental para poder avanzar en la comprensión de los procesos de exclusión y de discriminación contra la población Romá.

La segunda conclusión se refiere a los resultados empíricos del sistema de indicadores sobre prejuicio, discriminación y exclusión hacia los grupos Romá. Por una parte, y aunque se observa una gran discrepancia entre países, esta herramienta permite identificar aquéllos donde el antigitanismo se expresa con mayor gravedad e intensidad (sobre todo, en Croacia, Grecia y República Checa). Todos estos resultados, no obstante, han de conectarse con los contextos políticos, culturales, sociales y económicos que sustentan las actitudes y comportamientos racistas contra la población Romá y otros grupos víctimas del clima de odio e intolerancia creciente en algunos países europeos. Esta labor conllevaría la combinación del uso de indicadores con otras fuentes de información (cualitativas, legales, jurídicas y penales...) y abriría nuevas vías de análisis.

Por otra parte, la comparación entre países y las distintas dimensiones del antigitanismo revela importantes inconsistencias y paradojas que pueden deberse, junto a los problemas metodológicos ya señalados, a los efectos de los mecanismos de dominación que normalizan y naturalizan las desigualdades sociales y las discriminaciones étnicas. La hipótesis de la normalización del antigitanismo (muy relacionada con la idea del antigitanismo razonable) puede observarse en los países donde se produce una elevada discriminación y exclusión social declarada por la población Romá, en contraposición a una baja percepción por parte de la población general de que estos grupos se encuentren discriminados o de que exista discriminación étnica en el país (es el caso de República Checa, Bulgaria y Grecia). Por otra parte, la naturalización de la discriminación étnica y de las desigualdades de género se observa en la reducida 
identificación de situaciones discriminatorias entre el grupo más excluido y discriminado de toda Europa, y en especial, entre las mujeres Romá.

En suma, las fuentes existentes, aunque limitadas, son valiosas y fundamentales para avanzar en el conocimiento de esta importante problemática, sobre todo teniendo en cuenta la escasez de bibliografía específica al respecto. Ahora mismo, estas fuentes son las únicas disponibles para obtener datos a nivel macrosocial sobre la extensión y características del antigitanismo en Europa, pero sobre todo ponen en evidencia la persistente y generalizada situación de exclusión que enfrenta la población Romá en todos los ámbitos sociales. Por ello, se hace necesario el análisis de crítico de los instrumentos utilizados y avanzar en su mejora, pues el establecimiento de un sistema sólido de indicadores permitiría no solo contrastar las situaciones entre diferentes países, sino también su evolución a lo largo del tiempo y la comparación entre distintos grupos étnicos.

\section{BIBLIOGRAFÍA}

ALLIANCE AGAINST ANTIGYPSYISM (2016): "Antigypsyism. A Reference Paper”, UE, Alliance against Antigypsyism. Consulta: 21 de abril de 2019 (http://www. antigypsyism.eu).

ALLPORT, G.W. (1954/ 1991): The Nature of Prejudice, Cambridge, Mass, Addison-Wesley.

ALTER (2014): "Los perfiles de la discriminación en España. Análisis de la Encuesta CIS-3.000. Percepción de la discriminación en España", Ministerio de Sanidad, Servicios Sociales e Igualdad. Consulta 3 de mayo de 2019 (http://www.fundacioncives.org/rec/recursos/los-perfiles-de-ladiscriminacion-en-espa-a-analisis-de-la-encuesta-cis-3-000-percepcion-de-ladiscriminacion-en-espa-a.html)

ARDEVOL, E. (1986): "Vigencias y cambio en la cultura de los gitanos", en Entre la marginación y el racismo editado por T. San Román, Madrid, Alianza, pp. 61-107.

BERICAT, E. y JIMÉNEZ RODRIGO, M.L. (2019): The Quality of European Societies. A compilation of composite indicators, Switzerland, Springer.

BOURDIEU, P. (2007): El Sentido Práctico, Siglo XXI, Madrid. 
CANTÓN DELGADO, M. (2018): "Narrativas del Despertar gitano. Innovación religiosa, liderazgos gitanos y políticas de idoneidad", Revista Internacional de Sociología, 76(2), pp. 38-57.

CARO MAYA, P. y WERNER BOADA, S. (2018): "Kalí NGOs and the Spanish Model: A Resistant or Complacent Framework?", en A Reflexive History of the Romani Women's Movement: Struggles and Debate in Central and Eastern Europe, editado por A. Kóczçe, v. Zentai, J. Jovanovic y E. Vincze, Abingdon y New York, Routledge, pp. p. 227-246.

CARRERA, S., ROSTAS, I., y VOSYLIŪTĖ, L. (2017): “Combating Institutional Anti-Gypsyism Responses and promising practices in the EU and selected Member States", CEPS, Research Report, No 2017/08. Consulta 4 de mayo de 2019 (https://www.ceps.eu/wp-content/uploads/2017/05/RR201708_AntiGypsyism.pdf)

CEA D'ANCONA, M.A. (2009): "La compleja detección del racismo y la xenofobia a través de encuesta. Un paso adelante en su medición", Revista Española de Investigaciones Sociológicas, 125, pp. 13-45.

CEA D'ANCONA, M.A. y VALLES, M. (2018): "Evolución de la discriminación en España. Informe de las encuestas IMIO-CIS de 2013 y 2016", Instituto de la Mujer y para la Igualdad de Oportunidades. Consulta: 20 de junio de 2019 (http://www.inmujer.gob.es/actualidad/NovedadesNuevas/docs/2018/Evoluci onDiscrimEsp2018-0159.pdf).

CEMLYN, S., GREENFIELDS, M., BURNETT, S., MATTHEWS, Z., y WHITWELL, C. (2009): "Inequalities experienced by Gypsy and Traveller communities: A review". (Research report: 12), Equality and Human Rights Commission. Consulta: 13 de abril de 2019 (https://www.equalityhumanrights.com/sites/default/ fi les/research-report12-inequalitie s-experienced-by-gypsy-and-traveller-communities.pdf)

CIAIAN, P. y KANCS, D. (2016): "Causes of the Social and Economic Marginalisation: The Role of Social Mobility Barriers for Roma", Economics and Econometrics Research Institute (EERI) Research Paper. EERI RP 2016/03, Economics and Econometrics Research Institute (EERI), Brussels.

COMISIÓN EUROPEA (2017): "Revisión intermedia del Marco europeo de estrategias nacionales de integración de los gitanos", Comunicación de la Comisión al Parlamento Europeo y al Consejo, COM (2017) 458 final. $\begin{array}{lllll}\text { Consulta: } & 10 & \text { de } & \text { septiembre } & \text { de }\end{array}$ 
(https:/ec.europa.eu/transparency/regdoc/rep/1/2017/ES/COM-2017-458-F1ES-MAIN-PART-1.PDF)

COMISIÓN EUROPEA (2018): "Informe sobre la evaluación del marco de la UE para las estrategias nacionales de integración de los gitanos hasta 2020", Comunicación de la Comisión al Parlamento Europeo y al Consejo, COM 785 final. Consulta: 20 de mayo de 2019 (https://eur-lex.europa.eu/legalcontent/ES/TXT/PDF/?uri=CELEX:52018DC0785\&from=EN)

CONFERENCE OF EUROPEAN STATISTICIANS (CES) (2015):

"Recommendations for the 2020 Censuses of Population and Housing. Eurostat". Consulta: 3 de junio de 2019 (https://www.unece.org/publications/2020recomm.html)

CONSEJO DE EUROPA (2012): "Estimates and official numbers of Roma in Europe", UE updated July 2012. Consulta: 20 de mayo de 2019 (https://rm.coe.int/1680088ea9)

CORSI, M., CREPALDI, C., SAMEK LODOVICI, M., BOCCAGNI, P., VASILESCU, C. (2008): "Ethnic minority and Roma women in Europe: A case for gender equality? Final Report", European Commission. Consulta: 20 de mayo de 2019 (https://publications.europa.eu/en/publication-detail//publication/560f9472-1aa0-4ddb-a863-e92460df64dc/language-en)

CORTES GOMÉZ, I. y END, M. (2019): "Introduction: Contemporary Dimensions of Antigypsyism in Europe", en Dimensions of Antigypsyism in Europe, editado por Cortés Gómez, I. y End, M., European Network against Racism (ENAR) and the Central Council of German Sinti and Roma, pp. 1928. Consulta: 20 de mayo de 2019 (https://www.enar-eu.org/BookDimensions-of-Antigypsyism-in-Europe)

DECADE OF ROMA INCLUSION SECRETARIAT FOUNDATION. (2015):

"Roma Inclusion Index, 2015". Consulta: 20 de mayo de 2019

(https://www.rcc.int/romaintegration2020/files/user/docs/Roma\%20Inclusion \%20Index\%202015.pdf=)

EICHLER, M. y BURKE, A. (2006): “The Bias Free Framework. A new analytical tool for global health research", Canadian Journal of Public Health, 97(1), pp. 63-68.

END, M. (2014): "Antigypsyism in the German Public Sphere. Strategies and Mechanisms of Media Communication. [Short Version. Approach, Examples 
and Findings of the Study. Translated by William Templer]". Documentation and Cultural Centre of German Sinti and Roma. Heidelberg.

ESCOBAR BALLESTA, M., GARCÍA RAMÍREZ, M., ALBAR MARÍN, M.J. Y PALOMA, V. (2019): "Salud sexual y reproductiva en mujeres gitanas: el programa de planificación familiar del polígono sur", Gaceta Sanitaria, 33 (3), pp. 222-228.

EUROPEAN COMMISSION AGAINST RACISM AND INTOLERANCE (ECRI): (2011): "Recomendación de Política General № 13 de la ECRI sobre la lucha contra el antigitanismo y las discriminaciones contra los Romaníes/Gitanos". Consejo Europeo. Estrasburgo. Consulta: 2 de abril de 2019 (https://rm.coe.int/ecri-general-policy-recommendation-no-13-oncombating-anti-gypsyism-an/16808b5aef)

EUROPEAN COMMISSION AGAINST RACISM AND INTOLERANCE (ECRI) (2018): "Report on Croatia. 2018". Consulta: 25 de septiembre de 2019 (https://rm.coe.int/fifth-report-on-croatia/16808b57be)

EUROPEAN UNION AGENCY FOR FUNDAMENTAL RIGHTS (FRA) (2013): "Roma Pilot Survey Technical report: methodology, sampling and fieldwork". Consulta: 3 de junio de 2019 (https://fra.europa.eu/sites/default/files/fra-2014roma-pilot-survey-technical-report en.pdf)

EUROPEAN UNION AGENCY FOR FUNDAMENTAL RIGHTS (FRA) (2014): "Discrimination against and living conditions of Roma women in $11 \mathrm{EU}$ Member States Roma survey - Data in focus". Consulta: 3 de junio de 2019 (https://fra.europa.eu/en/publication/2014/discrimination-against-and-livingconditions-roma-women-11-eu-member-states)

EUROPEAN UNION AGENCY FOR FUNDAMENTAL RIGHTS (FRA) (2017a): "Second European Union Minorities and Discrimination Survey (EU-MIDIS II): Main results". Consulta: 3 de junio de 2019 (http://fra.europa.eu/sites/default/files/fra uploads/fra-2017-eu-midis-iimain-results en.pdf=

EUROPEAN UNION AGENCY FOR FUNDAMENTAL RIGHTS (FRA) (2017b): "Second European Union Minorities and Discrimination Survey Technical report". Consulta: 3 de junio de 2019 (https://fra.europa.eu/sites/default/files/fra uploads/fra-2017-eu-midis-iitechnical-report en.pdf) 
FAY, R. y KAVANAGH, L. (2019): "If We Are Not Counted, We Do Not Count: A Bottom-up Approach to Ethnic Equality Monitoring in Ireland", en Dimensions of Antigypsyism in Europe, editado por Cortés Gómez, I. y End, M., European Network against Racism (ENAR) and the Central Council of German Sinti and Roma, pp. 231-245. Consulta: 20 de mayo de 2019 (https://www.enar-eu.org/Book-Dimensions-of-Antigypsyism-in-Europe)

FREDMAN, S. (2016): "Intersectional Discrimination in EU Gender Equality and Non-Dscrimination Law", Brussels, European Commission, Directorate General for Justice and Consumers. Consulta: 12 de abril de 2019 (https://publications.europa.eu/en/publication-detail/-/publication/d73a9221b7c3-40f6-8414-8a48a2157a2f)

FUNDACIÓN SECRETARIADO GENERAL GITANO (FSGG) (2016): "Discriminación y comunidad gitana", Madrid. Consulta: 12 de septiembre de 2019

(https://www.gitanos.org/upload/72/77/Informe discriminacion 2016 ok.pdf )

FUNDACIÓN SECRETARIADO GENERAL GITANO (FSGG) (2018): "Discriminación y comunidad gitana. 2018", Madrid. Consulta: 12 de septiembre de 2019 (https://gitanos.org/upload/14/89/Informe de discriminacion 2018 ingles . pdf)

FUNDACIÓN SECRETARIADO GENERAL GITANO (FSGG): "La comunidad gitana". Website. Consulta 20 de noviembre de 2019 (https://www.gitanos.org/la comunidad gitana/gitanos hoy.html.es)

GAY BLASCO, P. (2011): "Agata's Story: singular lives and the reach of the "Gitano Law", Journal of the Royal Anthropological Institute, 17 (3), pp. 445461.

GONZÁLEZ ENRÍQUEZ, C. (2010): "La integración y la migración de la población gitana en Europa". Análisis del Real Instituto Elcano (ARI), 170, pp. 1-9. Consulta: 11 de noviembre de 2019 (http://www.realinstitutoelcano.org/wps/portal/rielcano es/contenido?WCM GLOBAL CONTEXT=/elcano/elcano es/zonas es/demografia+y+poblacion/ $\underline{\operatorname{ari170-2010})}$

GRECO, S., ISHIZAKA, A., TASIOU, M., y TORRISI, G. (2019): “On the methodological framework of composite indices: A review of the issues of 
weighting, aggregation, and robustness". Social Indicators Research, 141(1), pp. 61-94.

HADZIAVDIC, H. (2012): "Gypsies as "marginal man" in works by Georg Simmel and Robert Park", Rocky Mountain Review, 66 (1), pp. 32-44.

IVANOV, A.; KELLER, S.; TILL-TENTSCHERT, U. (2015): "Roma poverty and deprivation: the need for multidimensional anti-poverty measures", OPHI working paper no 96. University of Oxford. Consulta: 3 de junio de 2019 (https://ora.ox.ac.uk/objects/uuid:79d73f84-5a39-472d-82d5-fe2c68824df3)

JOHNSON, T. P., y VAN DE VIJVER, F. J. (2003): "Social desirability in crosscultural research", en Cross-cultural survey methods, editado por J. A. Harkness, F. van de Vijver, y P. Ph. Mohler, Hoboken, NJ, John Wiley and Sons, pp.195-204.

KAPRALSKI, S. (2016): “The evolution of anti-gypsyism in Poland: From ritual scapegoat to surrogate victims to racial hate speech?", Polish Sociological Review, 193(1), pp. 101-117.

KÓCKSÉ, A. y POPA, R.M. (2009): "Missing intersectionality. Race/Ethnicity, gender, and class in current research and policies on Romani Women in Europe", Central European University. Consulta: 3 de junio de 2019 (https://cps.ceu.edu/publications/policy-studies/missing-intersectionality)

LAPARRA, Miguel et al. (2007): "Una propuesta de consenso sobre el concepto de exclusión. Implicaciones metodológicas", Revista Española del Tercer Sector, 5, pp. 15-49.

LAPARRA, M. (coord.) (2007): "Diagnóstico social de la comunidad gitana en España. Un análisis contrastado de la Encuesta del CIS a hogares de población gitana 2007", Ministerio de Sanidad, Política Social e Igualdad. Consulta: 2 de junio de 2019 (https://www.mscbs.gob.es/ssi/familiasInfancia/PoblacionGitana/docs/diagnos ticosocial autores.pdf)

LA PARRA, D., GIL, D., y JIMÉNEZ, A. (2013): “Los procesos de exclusión social y la salud del pueblo gitano en España”, Gaceta Sanitaria, 27 (5), pp. 385-386.

LAURITZEN, S. M. y NODEALAND, T. S. (2018): "What is the problem represented to be?" Two decades of research on Romá and education in Europe", Educational Research Review, 24, pp. 148-169. 
LAZARSFELD, P. (1979): "De los conceptos a los índices empíricos", en Metodología de las ciencias sociales. I. Conceptos e índices, editado por Boudon, R. y Lazarsfeld, P., Barcelona, Laía, pp. 35-46.

MAKKONEN, T. (2016): European handbook on equality data. 2016 revision, Publications Office of the European Union, Luxembourg. Consulta: 20 de mayo de 2019 (https://ec.europa.eu/newsroom/just/document.cfm?action=display\&doc $i d=4$ $\underline{3205}$ )

MESA DE MUJERES GITANAS POR LA IGUALDAD (2018). "La ciudad de Madrid contra la violencia machista". Consulta: 5 de diciembre de 2019 https://www.gitanos.org/upload/60/47/recomendacionesVGmesagitanas2019. pdf

MINISTERIO DE SANIDAD, SERVICIOS SOCIALES E IGUALDAD (MSSSI). (2018): "Hacia la equidad en salud. Disminuir las desigualdades en una generación en la comunidad gitana. Resumen divulgativo de Estudio comparativo de las Encuestas Nacionales de Salud a población gitana y población general de España, 2014", Ministerio de sanidad y servicios sociales e igualdad: Madrid.

NARDO, M., SAISANA, M., SALTELLI, A., TARANTOLA, S, HOFFMANN, A. y GIOVANNINI, E. (2008): Handbook on Constructing Composite Indicators: Methodology and User Guide, OCDE. Consulta: 20 de mayo (https://www.oecd.org/els/soc/handbookonconstructingcompositeindicators methodologyanduserguide.htm)

OPEN SOCIETY EUROPEAN POLICY INSTITUTE (2017): "Revisiting the EU Roma Framework: Assessing the European Dimension for the Post-2020 Future". Consulta: 20 de junio de 2019 (https://www.opensocietyfoundations.org/publications/revisiting-eu-romaframework-assessing-european-dimension-post-2020-future)

OPEN SOCIETY FOUNDATION (2012): Reducing Ethnic Profiling in the European Union: A Handbook of Good Practices. Consulta: 20 de junio de 2019 (https://www.justiceinitiative.org/publications/reducing-ethnicprofiling-european-union-handbook-good-practices)

PAGER, D. y SHEPHERD, H., (2008): "The sociology of discrimination: Racial discrimination in employment, housing, credit, and consumer markets", Annual Review of Sociology, 34 (1), pp. 182-209. 
PAVEE POINT TRAVELLER AND ROMA CENTRE (2016): Policy and Practice in Ethnic Data Collection and Monitoring: Counting Us in - Human Rights Count. Dublin: Pavee Point Traveller and Roma Centre.

POWER, C. (2004): Room to Roam: England's Irish Travellers. London: Brent Irish Advisory Service.

REUSS, A. y MACK, J. (2019): "Data collection on equality, discrimination and antigypsyism", en Dimensions of Antigypsyism in Europe, editado por Cortés Gómez, I. y End, M., European Network against Racism (ENAR) and the Central Council of German Sinti and Roma, pp. 246-260. Consulta: 20 de mayo de 2019 (https://www.enar-eu.org/Book-Dimensions-of-Antigypsyismin-Europe)

RICHARDSON, J. (2006): “Talking about Gypsies: The notion of discourse as control”, Housing Studies, 21(1), pp.77-96.

RIO RUIZ, M., (2018): "Antigitanismo y cambios en los derechos y condiciones escolares de la infancia gitana en España (1970-1995)", Historia y Política: Ideas, Procesos y Movimientos Sociales, 40, pp. 179-210.

RUSSELL, H., QUINN, E., KING O'RIAIN, R. y MCGINNITY, F. (2008): “The experience of discrimination in Ireland: analysis of the QNHS equality module". Dublin, Equality Authority/ESRI. Consulta: 12 de mayo de 2019 (https://www.esri.ie/system/files/media/file-uploads/201507/BKMNEXT120.pdf)

SORDO, T. (2018): "Guía sobre discriminación interseccional. El caso de las mujeres gitanas", Fundación Secretariado Gitano. Madrid. Consulta: 21 de mayo de 2019 (https://www.gitanos.org/upload/18/56/GUIA DISCRIMINACION INTERSE CCIONAL FSG.pdf)

SURDU, L. y MIHAI S. (2006): Broadening the Agenda: The Status of Romani Women in Romania, New York, Open society Institute. Consulta: 23 de mayo 2019 (https://www.opensocietyfoundations.org/publications/broadening-agendastatus-romani-women-romania)

UNITED NATIONS (2018). "A Human Rights-Based Approach to Data: Leaving No One Behind in the 2030 Development Agenda". United Nations Human Rights Office of the High Commissioner, Geneve, Consulta 23 de mayo de 2019 
(https://www.ohchr.org/Documents/Issues/HRIndicators/GuidanceNoteonAp proachtoData.pdf.)

UNITED NATION DEVELOPMENT PROGRAM (UNDP/PNUD) (2018): Human Development Indices and Indicators: 2018 Statistical Update. Technical notes. Consulta: 2 de Julio de 2019 (http://hdr.undp.org/sites/default/files/hdr2018 technical notes.pdf)

URBANOS-GARRIDO, R. (2016): "La desigualdad en el acceso a las prestaciones sanitarias. Propuesta para lograr la equidad”, Gaceta Sanitaria, 30(S1), pp. 2530.

URH, P.H. (2014): "'Everyone is blaming us!' Conceptualising current anti-roma racism in Europe and its necessary implications for anti-racist social work", Critical and Radical Social Work, 2(1), pp. 59-76.

VALENTINE, G. y MCDONALD, I. (2004): "Understanding Prejudice: Attitudes towards Minorities", Stonewall. Consulta: 22 de mayo de 2019 (http://www.stonewall.org.uk/documents/Understanding Prejudice.pdf)

VAN BAAR, H. (2014): "The Emergence of a Reasonable Anti-Gypsyism in Europe", en When Stereotype Meets Prejudice: Antiziganism in European Societies, editado por Agarin T., Stuttgart, Ibidem Verlag, pp. 27-44.

VAN DE KERK, G. y MANUEL, A. R. (2008): "A comprehensive index for a sustainable society: The SSI-the Sustainable Society Index", Ecological Economics, 66 (2-3), pp. 228-242.

WATSON, H.L. y DOWNE, S. (2017): "Discrimination against childbearing Romani women in maternity care in Europe: a mixed-methods systematic review", Reproductive Health, 14 (1), pp. 1-16.

WIEVIORKA, M. (1992): El espacio del racismo, Paidós, Barcelona.

WILKINSON, R. y PICKETT, K. (2019): Igualdad. Cómo las sociedades igualitarias mejoran el bienestar colectivo, Capitán Swing, Madrid. 
Recibido: 10 de septiembre de 2019

Aceptado: 15 de noviembre de 2019

María Luisa Jiménez Rodrigo es profesora de Sociología de la Universidad Granada. Licenciada en Ciencias Políticas y Sociología y doctora en Antropología Social y Cultural, ha desarrollado investigaciones sobre desigualdades de género en salud, políticas de inclusión educativa y diversidad cultural. Sus actuales líneas de investigación versan sobre discriminaciones múltiples en el ámbito de las políticas de empleo y las políticas de igualdad de género así como del uso de indicadores sociales aplicados al análisis de las desigualdades sociales.

Patricia S. Sánchez-Muros Lozano es profesora del Dpto. de Sociología de la Universidad de Granada. Realizó su doctorado en prejuicios étnicos hacia la minoría gitana entre escolares de Enseñanza Secundaria. Ha participado en diversos proyectos locales, autonómicos e internacionales sobre la minoría gitana, recibiendo reconocimiento académico con un premio nacional sobre Racismo y Educación por la Paz. Su interés investigador se centra en los prejuicios étnicos hacia la minoría gitana y en las desigualdades en el ámbito de la salud pública centradas en el suicidio, en donde ha participación en el proyecto EUREGENAS, dentro del 2o Programa Europeo sobre Salud Pública. 


\section{ANEXOS}

Tabla 1. Índices de antigitanismo en la UE, ordenados según presencia de población Romá. 2016.

\begin{tabular}{|c|c|c|c|c|}
\hline País & Porcentaje de población Romá ${ }^{1}$ & Actitudes antigitanistas & Discriminación declarada & Exclusion social \\
\hline Bulgaria & 9,94 & 48,1 & 3,8 & 59,4 \\
\hline Eslovaquia & 9,02 & 47,7 & 11,5 & 48,9 \\
\hline Rumanía & 8,63 & 37,7 & 7,0 & 56,9 \\
\hline Hungría & 7,49 & 41,2 & 7,6 & 49,4 \\
\hline República Checa & 1,90 & 61,8 & 13,1 & 45,4 \\
\hline España & 1,63 & 24,3 & 9,5 & 50,0 \\
\hline Grecia & 1,55 & 52,5 & 11,0 & 59,7 \\
\hline Irlanda & 0,84 & 27,5 & n.d & n.d \\
\hline Croacia & 0,79 & 33,3 & 16,9 & 69,4 \\
\hline Francia & 0,62 & 36,6 & n.d & 46,2 \\
\hline Letonia & 0,56 & 31,9 & n.d & n.d \\
\hline Suecia & 0,53 & 26,9 & n.d & n.d \\
\hline Portugal & 0,49 & 35,0 & 7,2 & 44,5 \\
\hline Austria & 0,42 & 43,3 & n.d & n.d \\
\hline Eslovenia & 0,41 & 31,7 & n.d & n.d \\
\hline Reino Unido & 0,36 & 24,6 & n.d & n.d \\
\hline Bélgica & 0,28 & 43,7 & n.d & n.d \\
\hline Italia & 0,25 & 47,0 & n.d & 57,5 \\
\hline Países Bajos & 0,24 & 31,1 & n.d & n.d \\
\hline Finlandia & 0,21 & 41,6 & n.d & n.d \\
\hline Alemania & 0,13 & 40,2 & n.d & n.d \\
\hline Chipre & 0,11 & 47,3 & n.d & n.d \\
\hline Polonia & 0,09 & 30,1 & n.d & 51,0 \\
\hline Lituania & 0,09 & 37,7 & n.d & n.d \\
\hline Estonia & 0,08 & 41,0 & n.d & n.d \\
\hline Luxemburgo & 0,06 & 25,7 & n.d & n.d \\
\hline Dinamarca & 0,05 & 37,6 & n.d & n.d \\
\hline Malta & 0,00 & 45,7 & n.d & n.d \\
\hline
\end{tabular}

${ }^{1}$ Datos del Consejo de Europa (2012). La cifra incluye población Romá local, grupos Romá (Sinti, Travellers, etc.) y migrantes Romá.

n.d: No disponible

Fuente: Elaboración propia a partir de diversas fuentes secundarias (véase cuadro 1 en anexo). 
Cuadro 1. Estructura del sistema de indicadores sobre antigitanismo en Europa. Dimensiones, subdimensiones, indicadores y fuentes de datos.

\begin{tabular}{|c|c|c|c|}
\hline Dimensión & Subdimensiones & Indicadores & Fuentes \\
\hline \multirow{6}{*}{$\begin{array}{l}\text { D1. Actitudes } \\
\text { antigitanistas }\end{array}$} & \multirow{3}{*}{$\begin{array}{l}\text { D.1.1Rechazo } \\
\text { interpersonal a población } \\
\text { Romá }\end{array}$} & $\begin{array}{l}\text { - Incomodidad frente a la situación de una persona de una minoría étnica ocupe un alto cargo } \\
\text { político. }\end{array}$ & $\begin{array}{l}\text { EB Discriminación } \\
(2016)\end{array}$ \\
\hline & & - Incomodidad en el trabajo con compañeros de trabajo de origen Romá. & $\begin{array}{l}\text { EB Discriminación } \\
(2016)\end{array}$ \\
\hline & & - Incomodidad con que un hijo o una hija tenga relaciones con una persona de origen Romá. & $\begin{array}{l}\text { EB Discriminación } \\
(2016)\end{array}$ \\
\hline & \multirow{3}{*}{$\begin{array}{l}\text { D1.2. Percepción de } \\
\text { discriminación social } \\
\text { contra población gitana }\end{array}$} & - Extensión de la discriminación en función del origen étnico. & $\begin{array}{l}\text { EB Discriminación } \\
(2016)\end{array}$ \\
\hline & & - El origen étnico como una desventaja para acceder a un empleo. & $\begin{array}{l}\text { EB Discriminación } \\
(2016)\end{array}$ \\
\hline & & - $\quad$ Tensión percibida entre grupos (\% de tensión percibida, algo + mucha). & Eurofound (2016) \\
\hline \multirow{15}{*}{$\begin{array}{l}\text { D2. Experiencias } \\
\text { de } \\
\text { discriminación }\end{array}$} & \multirow{4}{*}{$\begin{array}{l}\text { D.2.1. Acoso y violencia } \\
\text { por razones étnicas }\end{array}$} & - Experiencias de acoso en función del origen étnico/ inmigrante. Últimos 12 meses. & MIDIS II (2016) \\
\hline & & $\begin{array}{l}\text { - Conciencia de que algún familiar o amigo, haya sido insultado o recibido burlas. Últimos } 12 \\
\text { meses. }\end{array}$ & MIDIS II (2016) \\
\hline & & $\begin{array}{l}\text { Experiencias de ataques físicos en función del origen étnico/inmigrante en los últimos. } \\
\text { Últimos } 12 \text { meses. }\end{array}$ & MIDIS II (2016) \\
\hline & & $\begin{array}{l}\text { - Coincidencia de que un miembro de la familia, o un amigo, haya sido atacado físicamente. } \\
\text { Últimos } 12 \text { meses. }\end{array}$ & MIDIS II (2016) \\
\hline & \multirow{2}{*}{$\begin{array}{l}\text { D.2.2. Discriminación en } \\
\text { el sistema sanitario y } \\
\text { administración }\end{array}$} & - Discriminación en el uso de servicios sanitarios. Últimos 12 meses. & MIDIS II (2016) \\
\hline & & - Discriminación en el contacto con la administración. Últimos 12 meses. & MIDIS II (2016) \\
\hline & \multirow{2}{*}{$\begin{array}{l}\text { D2.3. Discriminación } \\
\text { laboral }\end{array}$} & - Discriminación al buscar un empleo. Últimos 12 meses. & MIDIS II (2016) \\
\hline & & - Discriminación en el trabajo. Últimos 12 meses. & MIDIS II (2016) \\
\hline & \multirow{3}{*}{$\begin{array}{l}\text { D2.4. Discriminación } \\
\text { educativa }\end{array}$} & - Discriminación en el trato con otros niños y niñas en la escuela. Últimos 12 meses. & MIDIS II (2016) \\
\hline & & - Discriminación con el contacto con las instituciones educativas. Últimos 12 meses. & MIDIS II (2016) \\
\hline & & - Discriminación en la asistencia a la escuela. Últimos 12 meses. & MIDIS II (2016) \\
\hline & $\begin{array}{l}\text { D.2.5. Discriminación en } \\
\text { vivienda }\end{array}$ & - Discriminación en la búsqueda de vivienda. Últimos 12 meses. & MIDIS II (2016) \\
\hline & \multirow{3}{*}{$\begin{array}{l}\text { D.2.6. Discriminación en } \\
\text { la interacción cotidiana }\end{array}$} & - Discriminación en el acceso a tiendas. Últimos 12 meses. & MIDIS II (2016) \\
\hline & & - Discriminación en el acceso a restaurantes y otros lugares de ocio. Últimos 12 meses. & MIDIS II (2016) \\
\hline & & - $\quad$ Discriminación en el uso de transporte público. Últimos 12 meses. & MIDIS II (2016) \\
\hline
\end{tabular}




\begin{tabular}{|c|c|c|c|}
\hline Dimensión & Subdimensiones & Indicadores & Fuentes \\
\hline \multirow{15}{*}{$\begin{array}{ll}\text { D3. } & \text { Exclusión } \\
\text { social } & \end{array}$} & \multirow{2}{*}{$\begin{array}{l}\text { D.3.1. Exclusión } \\
\text { educativa }\end{array}$} & - Abandono escolar temprano entre la población Romá. & $\begin{array}{l}\text { MIDIS II (2016) } \\
\text { Roma Survey (2011) }\end{array}$ \\
\hline & & - \% población Romá que no alcanza terminar secundaria o estudios terciarios. & MIDIS II (2016) \\
\hline & \multirow[b]{2}{*}{ D3.2. Exclusión laboral } & - Desempleo en los últimos cinco años entre la población Romá (\%). & MIDIS II (2016) \\
\hline & & $\begin{array}{l}\text { - Situación de no empleo asalariado (desempleo + cuidado a TC + otros trabajos no pagados) (\% } \\
\text { población Romá). }\end{array}$ & MIDIS II (2016) \\
\hline & \multirow{2}{*}{$\begin{array}{l}\text { D.3.3. Exclusión } \\
\text { económica }\end{array}$} & $\begin{array}{l}\text { - Personas de origen Romá en riesgo de pobreza (ingresos por debajo del 60\% de la media } \\
\text { nacional). }\end{array}$ & $\begin{array}{l}\text { MIDIS II (2016) } \\
\text { Roma Survey (2011) }\end{array}$ \\
\hline & & - Hogares Romá que no llegan a fin de mes. & $\begin{array}{l}\text { MIDIS II (2016) } \\
\text { Roma Survey (2011) }\end{array}$ \\
\hline & \multirow{3}{*}{$\begin{array}{l}\text { D.3.4. Salud y exclusión } \\
\text { del sistema sanitario }\end{array}$} & - Necesidades médicas no cubiertas, pese a que se necesitó. & Roma Survey (2011) \\
\hline & & - $\quad$ Problema de salud de larga duración. & MIDIS II (2016) \\
\hline & & - Limitaciones para la realización de actividades de la vida diaria. & MIDIS II (2016) \\
\hline & \multirow{2}{*}{$\begin{array}{l}\text { D.3.5. Vivienda y } \\
\text { exclusión residencial }\end{array}$} & - Vive en barrios o zonas segregadas. & MIDIS II (2016) \\
\hline & & - Vive en viviendas con problema de hacinamiento. & MIDIS II (2016) \\
\hline & \multirow{2}{*}{ D.3.6. Protección social } & - $\quad$ No recibió una ayuda cuando estuvo en desempleo. & Roma Survey (2011) \\
\hline & & - No recibe pensión (pública o privada) cuando llega a edad de jubilación. & Roma Survey (2011) \\
\hline & \multirow[t]{2}{*}{ D.3.7. Participación social } & $\begin{array}{l}\text { - No participación activa en un sindicato, organización política, una organización Romá u otra } \\
\text { organización. }\end{array}$ & Roma Survey (2011) \\
\hline & & - No votó en las últimas elecciones nacionales. & Roma Survey (2011) \\
\hline
\end{tabular}

Fuente: Elaboración propia 
Tabla 2. Índice de contexto antigitanista. Países de la UE. 2016.

\begin{tabular}{|c|c|c|c|}
\hline País & 1. Contexto antigitanista & 1.1. Rechazo interpersonal & 1.2. Percepción de discriminación étnica societal \\
\hline República Checa & 61,8 & 58,8 & 65,0 \\
\hline Grecia & 52,5 & 45,0 & 61,2 \\
\hline Bulgaria & 48,1 & 46,0 & 50,4 \\
\hline Eslovaquia & 47,7 & 40,8 & 55,8 \\
\hline Chipre & 47,3 & 39,0 & 57,5 \\
\hline Italia & 47,0 & 35,1 & 63,0 \\
\hline Malta & 45,7 & 31,1 & 67,1 \\
\hline Bélgica & 43,7 & 25,4 & 75,2 \\
\hline Austria & 43,3 & 27,7 & 67,6 \\
\hline Finlandia & 41,6 & 23,4 & 74,0 \\
\hline Hungría & 41,2 & 25,4 & 67,0 \\
\hline Estonia & 41,0 & 34,4 & 48,8 \\
\hline Alemania & 40,2 & 23,8 & 67,9 \\
\hline Rumanía & 37,7 & 28,6 & 49,8 \\
\hline Lituania & 37,7 & 41,5 & 34,2 \\
\hline Dinamarca & 37,6 & 19,3 & 73,3 \\
\hline Francia & 36,6 & 17,2 & 78,0 \\
\hline Portugal & 35,0 & 20,2 & 60,8 \\
\hline Croacia & 33,3 & 22,7 & 49,0 \\
\hline Letonia & 31,9 & 27,7 & 36,7 \\
\hline Eslovenia & 31,7 & 22,0 & 45,7 \\
\hline Países Bajos & 31,1 & 11,5 & 83,7 \\
\hline Polonia & 30,1 & 23,1 & 39,2 \\
\hline Irlanda & 27,5 & 14,6 & 51,9 \\
\hline Suecia & 26,9 & 8,8 & 82,3 \\
\hline Luxemburgo & 25,7 & 11,8 & 55,8 \\
\hline Reino Unido & 24,6 & 10,4 & 57,8 \\
\hline España & 24,3 & 9,8 & 59,8 \\
\hline
\end{tabular}

Fuente: Elaboración propia a partir del Eurobarómetro sobre Discriminación en la UE-28 (2016) y de la Encuesta de Condiciones de Vida

(Eurofound) (2016). 
Tabla 3. Experiencias de discriminación étnica en la población Romá. Índice y subíndices, según sexo. 2016.

\begin{tabular}{|c|c|c|c|c|c|c|c|c|c|c|c|c|}
\hline \multirow[b]{2}{*}{ País } & \multicolumn{3}{|c|}{ Indice de discriminación declarada } & \multicolumn{3}{|c|}{2.1 Violencia y acoso } & \multicolumn{3}{|c|}{ 2.2. Sanidad y administración } & \multicolumn{3}{|c|}{ 2.3. Empleo } \\
\hline & Total & Mujeres & Hombres & Total & Mujeres & Hombres & Total & Mujeres & Hombres & Total & Mujeres & Hombres \\
\hline Croacia & 16,9 & 10,2 & 19,3 & 20,4 & 13,1 & 26,5 & 11,4 & 10,4 & 13,0 & 16,2 & 8,5 & 19,6 \\
\hline República Checa & 13,1 & 13,3 & 12,3 & 27,1 & 23,0 & 31,7 & 8,9 & 6,3 & 11,5 & 13,0 & 13,4 & 11,6 \\
\hline Eslovaquia & 11,5 & 10,3 & 12,1 & 25,7 & 24,2 & 26,9 & 11,5 & 10,5 & 12,5 & 10,5 & 8,9 & 10,7 \\
\hline Grecia & 11,0 & 14,2 & 15,4 & 22,5 & 16,2 & 28,3 & 24,9 & 23,7 & 25,7 & 15,5 & 7,2 & 21,0 \\
\hline España & 9,5 & 9,3 & 9,7 & 10,6 & 10,5 & 11,2 & 5,9 & 5,5 & 7,1 & 8,1 & 7,7 & 8,1 \\
\hline Hungría & 7,6 & 6,9 & 7,6 & 8,1 & 6,5 & 9,9 & 5,3 & 5,9 & 3,5 & 7,2 & 5,3 & 8,5 \\
\hline Portugal & 7,2 & 7,6 & 6,6 & 4,5 & 5,1 & 3,9 & 9,2 & 8,9 & 9,5 & 22,7 & 20,2 & 23,0 \\
\hline Rumanía & 7,0 & 5,9 & 8,2 & 9,8 & 9,8 & 10,3 & 12,5 & 11,5 & 12,4 & 7,7 & 4,9 & 9,2 \\
\hline Bulgaria & 3,8 & 3,7 & 5,0 & 3,0 & 2,9 & 5,4 & 4,6 & 2,4 & 5,9 & 4,6 & 5,5 & 4,0 \\
\hline
\end{tabular}

(cont.)

\begin{tabular}{|c|c|c|c|c|c|c|c|c|c|}
\hline \multirow[t]{2}{*}{ País } & \multicolumn{3}{|c|}{ 2.4. Educación } & \multicolumn{3}{|c|}{ 2.5. Vivienda } & \multicolumn{3}{|c|}{ 2.6. Interacción social } \\
\hline & Total & Mujeres & Hombres & Total & Mujeres & Hombres & Total & Mujeres & Hombres \\
\hline Croacia & 16,3 & 9,5 & 24,7 & 29,0 & n.d & n.d & 13,3 & 10,1 & 16,0 \\
\hline República Checa & 7,9 & 8,7 & 7,6 & 25,0 & 37,0 & 14,0 & 8,0 & 9,0 & 7,7 \\
\hline Eslovaquia & 7,0 & 9,0 & 5,6 & 8,0 & 5,0 & 10,0 & 13,6 & 11,9 & 15,1 \\
\hline Grecia & 8,4 & 8,0 & 13,0 & 1,0 & n.d & 3,0 & 24,7 & 26,0 & 22,2 \\
\hline España & 6,3 & 5,9 & 6,1 & 14,0 & 15,0 & 13,0 & 16,5 & 16,8 & 16,6 \\
\hline Hungría & 7,6 & 6,3 & 9,3 & 8,0 & 6,0 & 9,0 & 10,6 & 13,4 & 7,9 \\
\hline Portugal & 1,6 & 1,6 & 1,6 & 5,0 & 6,0 & 4,0 & 18,6 & 21,3 & 16,1 \\
\hline Rumanía & 3,6 & 3,3 & 3,9 & 6,0 & n.d & 10,0 & 5,7 & 3,8 & 6,8 \\
\hline Bulgaria & 3,6 & 2,6 & 5,3 & 3,0 & 6,0 & n.d & 4,6 & 4,6 & 4,5 \\
\hline
\end{tabular}

n.d. Dato no disponible por el reducido número de muestra. Se sombrean los valores más elevados donde se observan diferencias de género.

Fuente: Elaboración propia a partir de la Encuesta MIDIS-II (2016) (FRA). 
Tabla 4. Índices de exclusión social entre la población Romá.

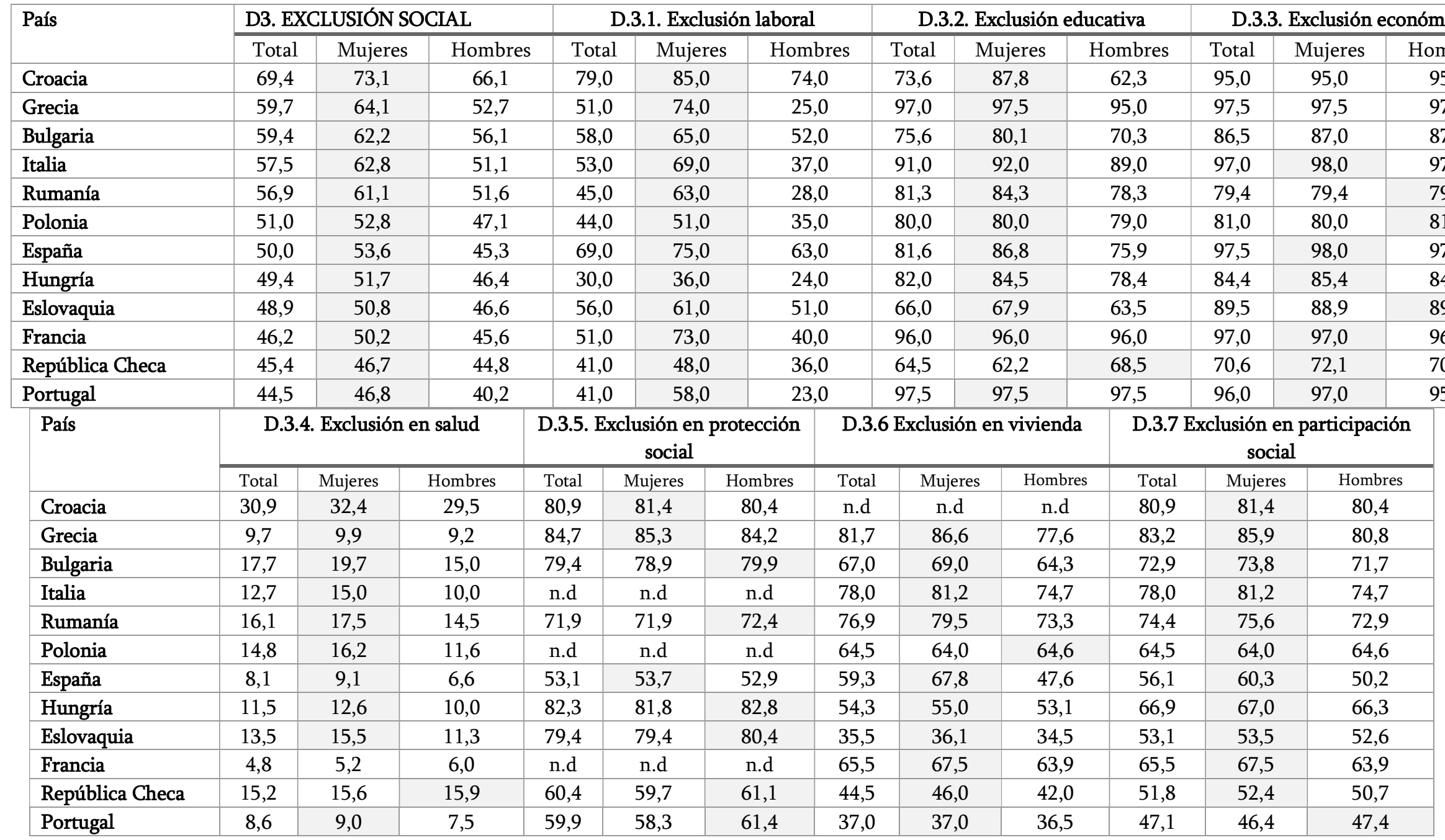

n.d. Dato no disponible por el reducido número de muestra. Se sombrean los valores más elevados donde se observan diferencias de género.

Fuente: Elaboración propia a partir de la Encuesta MIDIS-II (2016) y Roma Survey (FRA). 